NBER WORKING PAPER SERIES

\title{
IMPROVING THE QUALITY OF CHOICES IN HEALTH INSURANCE MARKETS
}

\author{
Jason Abaluck \\ Jonathan Gruber \\ Working Paper 22917 \\ http://www.nber.org/papers/w22917 \\ NATIONAL BUREAU OF ECONOMIC RESEARCH \\ 1050 Massachusetts Avenue \\ Cambridge, MA 02138 \\ December 2016
}

Corresponding Author: Jason Abaluck, Yale School of Management - Economics, 227 Church Street Apt 10H New Haven, CT 06510. jason.abaluck@yale.edu, 203-432-7811. We are grateful to Adrienne Sabety, Sean Sall and Christopher Behrer for exceptional research assistance, and to NIA grant number R01 AG031270 and the MODA Foundation for financial support. We are extremely grateful to Joan Kapowich for making this study possible, and to Mary French and Heidi Williams of the Oregon Educators Benefits Board (OEBB) for valuable information on program administration. We also thank seminar participants at ASHE, NBER, the University of Georgia, and the Canadian Public Economics Group for helpful comments. The views expressed herein are those of the authors and do not necessarily reflect the views of the National Bureau of Economic Research.

NBER working papers are circulated for discussion and comment purposes. They have not been peer-reviewed or been subject to the review by the NBER Board of Directors that accompanies official NBER publications.

(C) 2016 by Jason Abaluck and Jonathan Gruber. All rights reserved. Short sections of text, not to exceed two paragraphs, may be quoted without explicit permission provided that full credit, including $(\subset$ notice, is given to the source. 
Improving the Quality of Choices in Health Insurance Markets

Jason Abaluck and Jonathan Gruber

NBER Working Paper No. 22917

December 2016

JEL No. I11,I13

\begin{abstract}
$\underline{\text { ABSTRACT }}$
Insurance product choice is a central feature of health insurance markets in the United States, yet there is ongoing concern over whether consumers choose appropriately in such markets - and little evidence on solutions to any choice inconsistencies. This paper addresses these omissions from the literature using novel data and a series of policy interventions across school districts in the state of Oregon. Using data on enrollment and medical claims for school district employees, we first document large choice inconsistencies, with the typical employee foregoing savings of more than $\$ 600$ in their insurance plan choice. We then consider three types of interventions designed to improve choice quality. We first show that interventions to promote more active choice are unlikely to improve choice quality based on existing patterns of plan switching. We then implement a randomized trial of decision support software to illustrate that it has little impact on plan choices, largely because of consumer avoidance of the recommendations. Finally, we show that restricting the choice set size facing individuals does significantly reduce their foregone saving and total costs. This is not because individuals choose worse with larger choice sets, but rather because larger choice sets feature worse choices on average that are not offset by individual re-optimization.
\end{abstract}

Jason Abaluck

Yale School of Management

Box 208200

New Haven, CT 06520-8200

and NBER

jason.abaluck@yale.edu

Jonathan Gruber

Department of Economics, E52-434

MIT

77 Massachusetts Avenue

Cambridge, MA 02139

and NBER

gruberj@mit.edu 


\section{INTRODUCTION}

Insurance product choice is a central feature of health insurance markets in the United States. Approximately 50\% of U.S. residents get their coverage from an employer, and 55\% of those offered employer-sponsored insurance (ESI) have a choice of insurance plans. ${ }^{1}$ Those who buy private insurance outside of the employer setting traditionally had a large number of lightly regulated options. These choices have been more regulated and organized under the state and federal exchanges established by the Affordable Care Act (ACA), but the number of options remains substantial, with an average of 34 plans per county being offered on the exchanges in $2016 .^{2}$ The Medicare program that provides insurance coverage to approximately 42 million elderly and disabled Americans provides a choice between the traditional Medicare program and over 2,000 "Medicare Advantage" plans that provide a private alternative; the prescription drug plan that was added to Medicare in 2006 is offered as well through 866 stand-alone private prescription drug insurance plans. ${ }^{3}$ The lowest income Americans who are insured through Medicaid typically have a choice of a variety of managed care plans for their coverage, with 280 total managed organizations operating in 39 states. $^{4}$

The degree of insurance plan choice in the U.S. and around the world is a lively source of ongoing debate. Some advocate for a further devolution of insurance plan allocation to consumer choice, in even less regulated environments. On the supply-side, the literature has been particularly concerned with adverse selection and insurer concentration. There is considerable evidence on the

\footnotetext{
${ }^{1}$ Data from Kaiser Family Foundation, at http://kff.org/other/state-indicator/total-population/ and http://kff.org/health-costs/report/2015-employer-health-benefits-survey/

2 Calculated from 2016 individual QHP landscape data available at https://www.healthcare.gov/health-planinformation-2016/

${ }^{3}$ Data from Kaiser Family Foundation, at http://kff.org/report-section/whats-in-and-whats-out-medicare-advantagemarket-entries-and-exits-for-2016-appendix/ and http://kff.org/medicare/issue-brief/medicare-advantage-2016-dataspotlight-overview-of-plan-changes/ and http://kff.org/medicare/fact-sheet/the-medicare-prescription-drug-benefitfact-sheet/

${ }^{4}$ Data from Kaiser Family Foundation, at http://kff.org/other/state-indicator/total-medicaid-mcos/
} 
importance of adverse selection in health insurance markets (Cutler and Reber, 1998; Einav, Finkelstein and Levin, 2010) as well as whether it can be successfully mitigated by risk adjustment mechanisms (Glazer \& McGuire, 2000; Newhouse et al, 2012; Brown et al, 2014; Geruso and Layton, 2015; Geruso and McGuire, 2016). Mounting evidence also suggests that increased insurer concentration can lead to higher premiums (Dafny et al, 2012; Dafny et al, 2015).

On the demand-side, a fundamental question is whether consumers choose adequately or demonstrate choice inconsistencies by choosing plans which do not maximize their own long-run utility. Evidence for choice inconsistencies has mostly been demonstrated in other contexts, such as pension plans and cellular phone plans (Choi et al. 2002, Grubb and Osborne 2015), but there is a growing literature in the health insurance context as well. Most of this work has been focused on the case of prescription drug plan choice in the Medicare program. Abaluck and Gruber (2011) present reduced form facts and structural analysis consistent with large choice inconsistencies and foregone welfare for seniors choosing prescription drug plans; Ketcham et al. (forthcoming) and Abaluck and Gruber (forthcoming) clarify the sensitivity of these results to normative assumptions about the role of omitted characteristics and debate various specification checks of models of choice inconsistencies. Work by Handel (2013), Bhargava, et al (2015), and Handel and Kolstad (2015) document choice inconsistencies in the broader insurance context as well.

Importantly, however, there is little work on solutions to this key issue with health insurance plan choice. Essentially, there are three classes of potential solutions. The first is to promote active choice. Work by Handel (2013) and Abaluck and Gruber (2016) highlight the role of inertia as a barrier to resolving choice inconsistencies. If individuals are not actively revising their choices over time, then there could be dominated choices (Handel) or growing choice inconsistencies (Abaluck and Gruber). Therefore, one "benign" intervention could be to promote 
individuals to choose actively, in order to combat inertia. This could be done, for example, by forcing active reenrollment, rather than allowing passive reenrollment in the previous year's choice.

The second is to augment individual choice with decision support. Past work has suggested some potential for this type of intervention. ${ }^{5}$ But there is no work to date studying information provision about the explicit costs of alternative plans using actual choices in the context of medical insurance. Absent this research, it is impossible to know whether choice inconsistencies can be effectively resolved through these mechanisms in crucial policy settings like the ACA.

The final approach is to more aggressively shift the choice architecture to potentially limit the "damage" from inconsistent choices. One way to do so would be to limit the number of choices available to enrollees. Iyengar and Kamenica (2010) review evidence from outside health insurance which suggests that an individual's willingness to participate in a market decreases as the choice set for entry increases. They then present laboratory experiments and field data "that suggest larger choice sets induce a stronger preference for simple, easy-to-understand options." In the context of Medicare Part D, Ketcham (2015) finds that larger choice sets tended to increase switching behavior, but the variation in choice set sizes ranges from 46 to 55 , so that there may be little guidance for much smaller choice set sizes.

This paper addresses these omissions from the literature using novel data and a series of policy interventions across school districts in the state of Oregon. Beginning in October, 2008,

\footnotetext{
${ }^{5}$ Friedman and Frank (2016) conduct a hypothetical choice experiment studying broader health plan choices for seniors under Medicare Advantage - they find that participants given a list of the most inexpensive plans and possible savings from each are more likely to state an intention to choose those plans. Ericson et al. (2016) study a randomized information intervention in the ACA marketplace in Colorado. They find that information has little impact, but they provide information about the potential cost savings conditional on shopping rather than information about the relative costs of any particular plans. Perhaps the closest study to our own is Kling et al. (2012), which examines how consumers in a single hospital system responded to information about the costs of alternative prescription drug plans. They find a modest impact of information, yielding savings of a few hundred dollars and an 11 percentage point increase in switching rates.
} 
each of the roughly 240 school districts in Oregon selected a subset of plans to offer their employees from a menu of 9-13 plans that were made available to them at prices centrally negotiated by the state. Subject to some limitations, districts were free to choose the number and set of options to offer and the district contribution towards each option. The result is wide variation in choice sets and premiums available to roughly 63,000 school district employees in Oregon each year. In addition, in 2013, the state ran a randomized trial of new decision support software designed to improve the choices of employees across insurance plans.

We have gathered data from 2008-2013 on the complete enrollment and medical claims information for school district employees. We matched enrollment and claims data with data carefully collected from school district surveys and union contracts on the number of options and the district contributions towards those options over this period. We also designed and gathered results of the randomized trial of decision support software.

We use these data to accomplish two goals. The first is to assess whether the types of choice inconsistencies documented by Abaluck and Gruber (2011, 2016, forthcoming) extend from the narrower area of prescription drug plan choice to the broader health insurance plan choice environment. In fact, we find comparable results to the Part D context, with only $36 \%$ of employees making the cost minimizing choice and an average foregone savings of $\$ 1,012(38 \%$ of total out-of-pockets costs of $\$ 2,629)$. Structural models document significant choice inconsistencies even when controlling for other aspects of plan choice.

The second is to assess what types of interventions might reduce these choice inconsistencies. We consider interventions along each of the dimensions discussed above. The first is promoting choice among inertial enrollees. We bound the gains from choice by comparing 
the foregone savings of those who choose to switch versus those who are forced to switch due to a plan discontinuing. We find at most small improvements from more active choice.

The second intervention is to consider whether augmenting this active enrollment with an information intervention can improve outcomes. Our analysis of the randomized availability of a decision-support tool shows that it has little overall effect on the quality of health insurance choices. This results from both individuals' unwillingness to use the tool or follow its recommendations, as well as problems with the quality of the recommendations provided. We do find, however, that individuals are more likely to follow recommendations when they are better. This suggests that high quality information interventions could improve choices but would leave us far from solving the problem of choice inconsistencies.

Finally, we consider the more radical intervention of limiting choice set size. We study this using natural variation in choice set size within districts over time in a setting where premiums are set at the state level, allowing us to isolate demand-side effects. We know of no previous attempt to separate the demand-side impact of the number of choices on how well consumers choose from the supply-side impact on premiums via concentration. This is important, since policy instruments exist which could attempt to reduce the number or degree differentiation of available plans while maintaining competition such as auction mechanisms or standardization rules like those currently used in the ACA exchanges. We find that limiting plan options leads to both lower foregone savings and, more strikingly, reduced total costs paid by enrollees. We extend our structural model of choice to study how welfare varies as a function of a small number of sufficient statistics summarizing the existing choice set - including the number of plans - and the quality of choices. We find that our welfare results are almost completely driven by the fact that larger choice sets in our setting add plans which are worse on average; the fact that beneficiaries choose plans 
better tailored to their specific needs does little to offset this. We find little evidence of "choice overload" per se: consumers do not choose worse from larger choice sets; rather, the same choice function leads to worse choices if more bad options are available. This suggests that the problem is not choice overload, but rather that what is critical is how the decision-maker sets up the choice set. $^{6}$

Our paper proceeds as follows. Part II discusses the health insurance choices across Oregon school districts which provides the context for our study. Part III describes our data, while Part IV introduces our empirical strategy. Part V provides the results on choice inconsistency. Part VI then estimates the role of choice set limitations on choice quality, while Part VII performs a parallel analysis for the informed decision support intervention. Part VIII concludes.

\section{II: HEALTH INSURANCE BENEFITS AT THE OEBB}

The state of Oregon was divided into between 226 and 244 school districts, education service districts, or community colleges during our study period, with small variation from year to year. Districts had several classes of workers; a given employee is categorized as one of: administrator licensed, administrator non-licensed, classified, community college noninstructional, community college faculty, confidential, licensed, substitute, or superintendent. Within each type are both part-time and full-time employees. Most workers employed by school districts are a member of one of three unions, either the Oregon School Employees Association (OSEA), the Oregon Education Association (OEA), or the American Federation of Teachers Oregon (AFT).

\footnotetext{
6 This finding is consistent with the conclusions of Bhargava et al. (2015), who find many employees making dominated insurance choices at a large firm, and argue that individuals would have been better off in a single plan.
} 
Prior to 2008, districts and community colleges independently purchased plans for employees through the Oregon School Employees Association or one of two health plan trusts. Beginning in 2008, health insurance benefits, as well as life and disability coverage, long-term care insurance, an employee assistance program, and pre-tax savings accounts for each of these districts or community colleges are provided by the Oregon Educational Benefit Board (OEBB). The OEBB negotiates rates for the state for a variety of plans from several insurers. These plans are listed over time in Table I. From 2008-2013, there were between 9 and 13 options available from three insurers: Kaiser Permanente, a closed panel Health Maintenance Organization (HMO) that restricts patients to go to Kaiser hospitals and physicians; OMED (later MODA), a Preferred Provider Organization (PPO) plan that allows free choice of providers within a fairly broad statewide network; and Providence, a competing PPO plan.

As the table shows, the set of options a district could offer changed over time: OMED/MODA increased their plan offerings in 2013, Kaiser added one plan in 2009 and removed one plan in 2010, and Providence eventually withdrew from the choice set in 2011. The options available to a given beneficiary also changed from year to year based on statewide regulations and individual district choices. In addition to these medical plan options, OEBB also offers a choice of prescription drug plans, dental plans, and vision coverage. Appendix Table 1 summarizes the benefits structures of each of these options.

Each district was then given the option to offer up to 4 of those plans to their employees for 2008-2011. For 2012-2013 there was no cap on the number of medical plans a district could offer. Across all years, Kaiser plans were only offered in a subset of regions.

The district has other tools at its disposal that can impact insurance plan choices as well. One such tool is the rate at which the district will contribute towards plans. These contributions 
are negotiated with the unions representing workers in each district and are made public to employees before they enroll in health insurance for the upcoming year. Contribution structures differ substantially across districts. For most districts, for each employee type there is one flat contribution for all coverage tiers (employee, employee and child, employee and spouse, family). Districts could also vary the fixed contribution amount by coverage tier, and could offer either prorated or full contribution amounts to part-time employees. Districts could also offer a percentage contribution in which the district paid some percentage of the chosen plan premium, rather than a fixed dollar amount. This percentage contribution could either be constant for all employees or vary similarly to fixed contributions, by coverage tier and full time versus part time status. Districts could also establish a fixed employee contribution to the premium, in which case the district contribution would be the raw premium minus this fixed employee contribution and would vary based on the cost of the chosen plan. This fixed employee contribution could vary similarly to the district contributions above.

In addition, if the district offers OMED9/MMEDH (which were high deductible plans attached to a tax deferred health savings account), the district can decide on how much to contribute to the health savings account. Districts could also offer a Health Reimbursement Account (HRA) to beneficiaries in OMED/MODA plans other than the high deductible plan. If there was an excess district premium contribution (e.g. the negotiated amount a district contributes to an employee's premiums was greater than the raw premium) unions negotiated that either the complete excess, a percentage of the excess, or the excess up to a maximum value would be contributed by the district to an employee's HRA. Some districts made a fixed contribution to an HRA regardless of excess contributions. 
Enrollment in health insurance plans takes place during an open enrollment period that runs from August 15 th to September $15^{\text {th }}$ each fall. We have data on choices made by enrollees in open enrollments from fall 2008 through fall 2013. The default option for employees not making an active choice vary by district and year; unfortunately, these defaults are not observable to us.

\section{III: DATA}

We have collected data from a variety of sources for this analysis.

\section{Institutional Details on District Plan Structure and Contributions}

We received complete data on the plans offered by each district in each year to each employee type from OEBB. We then collected detailed data on the district contributions to employee premiums as well as district policies on HSAs and HRAs from two sources. First, with OEBB's assistance, we collected detailed surveys from each district. Surveys regarding district HSA and HRA policies was sent to each district's benefits manager. Second, we received from OEBB union contracts. These contracts contain the negotiated district contributions to represented employees as well as whether an HSA or HRA was available. We carefully combined these two sources of data, with priority to directly collected surveys because of the possibility that a contract had been amended, but the amendment was not publically available. We drop district, year, employee type observations for which we do not have data on the district contribution. We also drop observations for employees whose choice sets include only one plan option.

Table II shows the number of beneficiaries with each choice set size in each year. This table is tabulated among the final sample of policy holders included in our perfect foresight analysis.

In addition to variation in the plans available to a beneficiary (choice set), districts vary widely in their contribution policy. While about $96 \%$ of policy holders in each year were in districts 
with a fixed district contribution, the value of that contribution varied. Between $2.3 \%$ and $5.4 \%$ of policy holders in each year were in districts with a percentage district contribution, and the remaining $0-1.6 \%$ of policy holders were in districts with a fixed policy holder contribution.

As noted above, another source of differentiation across districts is their contributions towards the HSA that is associated with plan OMED 9/MODA H or the HRA that could be offered to policy holders with other OMED/MODA plans. Among policy holders that were offered an HSA, $13.7 \%$ were offered no district contribution. $45.8 \%$ were offered only a district contribution calculated as a percentage of the excess district contribution to premiums (typically 100\%); 36.6\% of policy holders received a fixed district contribution to their HSA, and the remaining $3.9 \%$ of policy holders were offered a percentage of the excess district premium contributions plus a fixed district contribution to the HSA.

A district could offer an HRA to policy holders that chose OMED/MODA plans other than the high deductible plan, and could also offer a district contribution to that HRA. Among policy holders offered an HRA, $23.7 \%$ were offered no district contribution, $28.2 \%$ were offered a contribution calculated as a percentage of the excess district contribution to premiums (typically $50 \%), 8.1 \%$ were offered a $100 \%$ of the excess minus a fixed dollar amount, and $40.0 \%$ were offered a fixed district contribution ranging from $\$ 480$ - $\$ 4,800$ per year.

\section{Enrollment and Claims data on OEBB Employees}

To analyze choice of plan, we gathered a complete universe of enrollment and claims data for OEBB employees over the 2008-2013 period. We conduct analyses on two slightly different samples. First is a "perfect foresight" sample. In this analysis we use a beneficiary's year t claims

to model plan choice in year t. Alternatively, we also conduct some analyses that rely on a beneficiary's year t-1 claims to model year t plan choice; these methods are described in detail 
below, but are relevant here in that they require a sample with complete data for two continuous years, one prior to and one following plan choice, while the perfect foresight analysis requires only one year of complete data following plan choice. Both samples begin with 90,333 employees and a total of 384,807 employee/year combinations. Appendix Table 2 describes sample selection. We do not have data for 2007 and thus cannot create the "backwards looking" sample for that year; the selection criteria is therefore identical except for the step 8.

\section{Measuring Premium and Out of Pocket Costs}

There are a variety of issues that arise in the measurement of premiums and out of pocket costs. Direct premium payments are determined by the difference between plan cost and district contributions, as discussed above. But districts often also make separate contributions to the HSA account included in the OMED 9/MODA H plan and the HRA that could be offered with other OMED/MODA plans. As described above, we have carefully collected data on district policies for how any excess district contribution to premiums is deposited into these savings accounts. We then apply federal legal maximum amounts to these accounts, to arrive at a final dollar value for the amount (which varies by the raw premium of the plan selected and district specific policies) by which a district could fund a savings account. Beneficiaries can use this amount to offset out of pocket costs, so after calculating the raw out of pocket costs faced by a beneficiary in each plan in their choice set, we subtract the district contributed amount in a beneficiary's savings account to arrive at the net out of pocket costs to a beneficiary.

Another issue is treatment of dental \& vision premiums. Given the small premium relative to medical and prescription drug, we assume that dental and vision plans are of secondary 
importance in the choice of a health insurance plan. Therefore, we assume that an individual will enroll in the same dental and vision plan, regardless of the medical plan in which they enroll. ${ }^{7}$

The major issue with measuring out of pocket costs is determining the proper model of expectations. We consider three different models of expectations: perfect foresight, perfect backcast and rational expectations. In the perfect foresight model, we assume that enrollees know exactly what their out of pocket costs will be in the coming year and run their realized claims through a calculator in each plan to determine out of pocket costs. In the perfect backcast model, we assume that enrollees believe that the coming year's claims will be identical to the prior year; to determine out of pocket costs, we run the prior year claims through each of the plans in the enrollee's choice set.

The rational expectations model assumes that enrollees forecast a distribution of possible out of pocket costs for each plan given the information available at the time when they choose. To create this distribution we use a software program developed by Johns Hopkins Medical School that predicts individual risk for future medical expenditures using past expenditure and demographics, as in Handel (2013). ${ }^{8}$ This software develops individual risk scores for future health care expenditure. By creating groups of individuals who are similarly at risk based on the Johns Hopkins software predicted risk score, and using our calculator to model costs in all available plans for randomly selected individuals from each group, we can create distributions of expected

\footnotetext{
${ }^{7}$ We do not observe chosen dental and vision plans prior to 2010. To calculate this premium cost prior to 2010, we calculate enrollment weighted average dental and vision premiums in each district and employee type for all dental and vision plans and for all non-Kaiser dental and vision plans with plan selection weights based on observed 2010 enrollment. If a beneficiary is enrolled in a Kaiser medical plan, we apply the all-plan weighted average dental or vision premium, and if a beneficiary is enrolled in a non-Kaiser medical plan, we apply the non-Kaiser weighted average dental or vision premium. After 2010, we apply the chosen dental or vision premium to all counterfactual plans, unless the counterfactual medical plan is non-Kaiser and the chosen medical plan was Kaiser - in which case the Kaiser dental or vision plan would not be available. In these cases we apply the mean enrollment weighted average of available non-Kaiser dental or vision plan premiums.

${ }^{8}$ Johns Hopkins ACG (Adjusted Clinical Groups) Case-Mix System. http://acg.jhsph.org/
} 
expenditures for each group of similarly at risk individuals. We use 3 methods and 3 draw sizes, resulting in 9 versions of these distributions to test sensitivity; all yield very similar results (See Appendix Table 3).

For the results in this paper, we create deciles of each of the three dimensions of risk and add an eleventh category in each dimension for zero costs. We then regress year t costs on these three categorical variables (calculated based on year t-1 claims) and generate a predicted cost in year t. Next we create deciles of this predicted cost variable to yield 10 groups of similarly at risk individuals. We then randomly sample with replacement 2,000 individuals from each cell. These randomly drawn individuals are all modelled as if they were individual policy holders in all available plans to create 2,000 estimates of out of pocket costs in every plan $\mathrm{x}$ cell combination. An observation for every plan in a beneficiary's choice set is then matched to the 2,000 estimates of out of pocket costs for their cell. Costs are then summed across families for each draw. Finally, family out of pocket and deductible maximum's are imposed on total family costs. With these constructed rational expectations measures of out of pocket costs, we can then assess choices against the mean and variance of the distribution of expected costs to investigate preferences for risk protection.

Another issue is the fact that there are very meaningful differences in provider networks across plans. Provider networks are identical within insurer with one exception; in 2011 and 2012 plan OMED4 was a limited network plan with a narrower network than other OMED plans. We can therefore include insurer fixed effects to capture the overall impact of these differences. But this will not allow us to capture individual-specific variation in the value of broader networks that may be correlated with our other parameters of interest in ways difficult to capture in any 
parametric specification. Thus, we report separately our results below looking at all plans as well as only plans offered by the largest single insurer, OMED/MODA. ${ }^{9}$

\section{IV: EVIDENCE OF CHOICE INCONSISTENCIES}

\section{Facts on Overspending}

We begin by presenting the basic facts on overspending, defined as the total costs to the beneficiary in the chosen plan minus the total cost to the beneficiary in the cost minimizing plan. For each policy holder in our data, we use our calculator to assign the net premium plus out of pocket costs of each option in their choice set. We then compare this quantity for the chosen plan to the lowest cost plan in their choice set, and compute the difference, for each model of expectations.

As Figure I shows, we find substantial overspending across all methods of modeling expected out of pocket costs. Assessing the chosen plan relative to all plans yields mean overspending between $\$ 940$ and $\$ 1,012$. Limiting to OMED/MODA only plans (which we will refer to as MODA hereafter) to avoid concerns about across insurer network differences, we still observe mean overspending between $\$ 565$ and $\$ 603$.

\section{Choice Model}

Of course, these facts on overspending are not by themselves dispositive because of other differences across plans; even within the MODA plans, the variance in outcomes may be lower for plans with higher measures overspending and may provide value to consumers. To address these concerns, we turn to a structural model of plan choice.

\footnotetext{
${ }^{9}$ The results for OMED/MODA only are identical if OMED4 is excluded from the choice set for 2011 and 2012.
} 
Our empirical framework follows the approach of Abaluck and Gruber (2011, 2016). Define the Gross Premium as the premium listed on the plan design document and define Net Premium $=\max \{0$, Gross Premium - Employer Contribution $\}$ as the amount the beneficiary actually pays. Additionally, define Residual Premium $=$ Net Premium Gross Premium. We will allow consumer utility to vary as a function of both the gross premium and the residual premium. If these have equal coefficients, then we could equivalently write utility as a function only as a function of the net premium.

We also distinguish between "fuzzy" and "sharp" inertia. In the "sharp" inertia case, there is a constant plan name which is identical to what was chosen by the beneficiary in the previous year (we denote the plan chosen by beneficiary $i$ in year $t$ by $c_{i t}$ ). In the "fuzzy" inertia case, though all of the plans have been relabeled, the chosen plan looks quite similar to a plan that was chosen in the previous year and may be a default depending on the district. ${ }^{10}$

Positive utility in our model is given by:

$$
\begin{aligned}
u_{i j t} & =\beta_{0}\left(J_{i}\right) \text { Gross Premium }_{i j t}+\beta_{1}\left(J_{i}\right) \text { Residual Premium } \\
i j t & +\beta_{2}\left(J_{i}\right) E(O O P)_{i j t} \\
& +\beta_{3}\left(J_{i}\right) \text { Var }_{i j t}+d_{j t}+\xi_{i j=c_{i(t-1)}}\left(J_{i}\right)+\epsilon_{i j}
\end{aligned}
$$

Utility depends firstly on the gross and residual premium terms, both of which vary by plan and tier. Utility additionally depends on the mean and variance of out of pocket costs (or in the case of the perfect backcast or perfect foresight model, just the mean since there is no uncertainty),

\footnotetext{
${ }^{10}$ For example, ODS medical plan 3 in 2012 had individual and family deductibles of $\$ 200$ and $\$ 600$ respectively, $\$ 1,500$ and $\$ 4,500$ in-network individual/family OOP max, $\$ 3,000$ and $\$ 9,000$ out of network individual/family OOP max, and modal cost sharing of $20 \%$ coinsurance. After changed names, MODA medical plan A in 2013 had individual and family deductibles of $\$ 200$ and $\$ 600$ respectively, $\$ 2,000$ and $\$ 6,000$ in-network individual/family OOP max, $\$ 4,000$ and $\$ 12,000$ out of network individual/family OOP max, and modal cost sharing of $20 \%$ coinsurance. We consider these two plans to be similar enough that individuals choosing MMEDA in 2013 after ODS3 in 2012 are categorized as "fuzzy" inertial. We link plan ODS3 to MMEDA, ODS7 to MMEDC, ODS8 to MMED E and ODS9 to MMED H in this manner. However, ODS plans 4-6 do not map cleanly to a 2013 plan, and no 2012 plan maps cleanly to plans MMED B, MMED D, MMED F and MMED G. See Appendix table 1 for plan characteristics.
} 
on plan-year fixed effects $d_{j t}$, on the fuzzy and sharp inertia dummies $\xi_{i j=c_{i j}(t-1)}$ and on the idiosyncratic error terms $\epsilon_{i j}$. Finally, all of the structural coefficients in the model are allowed to vary with the choice set size $J_{i}$.

In our baseline specifications, we assume that normative utility in money-metric terms is given by:

$$
u_{i j t}^{N}=\text { Net Premium }_{i j}+E(O O P)_{i j t}-\frac{\beta_{3}}{\beta_{0}} \operatorname{Var}_{i j t}
$$

This embeds four normative assumptions:

Assumption \#1: A dollar of premiums has the same normative utility impact as a dollar of out of pocket costs. Additionally, a dollar of gross premiums has the same normative utility impact as a dollar of residual premiums. A dollar is a dollar regardless of its providence (at least once we control for risk).

Assumption \#2: The inertia terms reflect inattention rather than adjustment costs and so are not relevant to utility. This is a standard assumption which follows our previous work as well as other papers in this literature (such as Handel and Kolstad 2015). Alternatively, one could interpret the welfare losses we calculate among inertial consumers as adjustment costs.

Assumption \#3: Financial characteristics of plans are not relevant for utility. Conditional on the individualized mean and variance of out of pocket exposure for a given plan, individuals should not independently value features such as deductibles and copayments; individual should only care about such plan characteristics to the extent that they affect them, not more generically. ${ }^{11}$

Assumption \#4: The other omitted characteristics - including plan fixed effects - are not relevant to utility. We believe that this assumption is defensible conditional on insurer but less defensible

\footnotetext{
${ }^{11}$ Of course, this is only true to the extent that we properly measure the uncertainty properties of different plans, of which the variance is only one summary measure. We have explored a wide variety of other measures of uncertainty, such as 90-10 difference, and find similar results.
} 
in the across insurer results given network differentiation. Conditional on choosing a MODA plan, physician network and other non-financial characteristics of plans are held constant - so the only important source of differentiation are the financial characteristics which we observe. In comparing across insurers, there is an important difference that we don't observe: network breadth. In particular, enrollees in Kaiser insurance plans are much more restricted in their choice of providers than are those in other plans. We will attempt to control for this in our analysis with plan fixed effects, but this does not fully capture heterogeneity in the valuation that consumers place on these characteristics. Therefore, we will consider analyses both restricting only to MODA plans and using the entire choice set.

\section{Evidence of Choice Inconsistencies and Welfare Consequences}

Table III shows the structural coefficients from estimation of the positive utility equation (equation 1). For plans with small market share, these coefficients can be interpreted as the percentage change in choice probabilities induced by a change in the "x" variable. For example, a $\$ 100$ increase in gross annual premiums leads to a 7-8\% reduction in the probability that a plan is chosen. We report results in our perfect backcast, perfect foresight and rational expectations models, and including all plans or restricting just to MODA plans so that all available options are offered by a single insurer. We include the variance term only for the rational expectations measure, since it is not computed for the other measures. All specifications include plan $\mathrm{x}$ tier and plan x year fixed effects. ${ }^{12,13}$

\footnotetext{
${ }^{12}$ The coefficients on plan characteristics such as the deductible, out of pocket max and copay are recovered by fixing the coefficients other than plan characteristics at their estimated value reported in the table, omitting the plan dummies and including these characteristics. This is equivalent to a weighted regression of the fixed effects on auxiliary plan characteristics.

${ }^{13}$ The gross premium is constant across districts and is identified by variation across tier, plan and year. The residual premium varies across districts, tier, plan and year based on district contribution policy. The OOP term varies across individuals as well as districts/tier/plan/year.
} 
The main results in all specifications are as follows: as in Abaluck and Gruber (2011) and (2016) we find (a) a large gap between the coefficient on premiums and out of pocket costs, (b) a high degree of inertia, and (c) a large willingness to pay for financial plan characteristics even after controlling for the out of pocket consequences of those characteristics. In terms of (a), we find that in every specification the coefficient on the gross premium is significantly larger than the coefficient on out of pocket costs, and is often several times larger. In terms of (b), we find consistently significant and sizeable inertia coefficients; for example, in the MODA only rationalexpectations specification, consumers are willing to pay $\$ 1,766$ to remain in the same plan. And in terms of (c), we find that 17 of 18 coefficients on fixed plan cost-sharing characteristics are significant and right signed; for example, once again turning to the MODA only rationalexpectations specification, consumers respond to a $\$ 10$ increase in primary care copays 22 times more than a $\$ 10$ increase in premiums after conditioning on the individualized out of pocket cost consequences. In other words, beneficiaries are extremely responsive to the copays listed for primary care visits, but their responsiveness does not vary much with the number of primary care visits they will actually make (and thus the individualized out of pocket cost coefficient is very small).

A new result here is that we find that, while consumers are fairly responsive to gross premiums (the number listed on plan design spreadsheets next to a plan), they are fairly insensitive to residual premiums, which vary conditional on gross premiums to the degree that premium contributions from employers "zero out" some plans and not others. As with out of pocket costs, this suggests that consumers are either not fully informed about what these contributions are or are failing to properly compute their consequences. 
The second panel of Table III computes foregone welfare given the normative utility function specified in the normative utility equation (equation 2) as well as the case where the variance term is assumed to be zero (in the perfect backcast model there is no variance). We find that including the variance makes essentially no difference - the measured degree of risk aversion is extremely small - and we find foregone welfare of $\$ 940-\$ 1,010$ relative to all plans and $\$ 560$ $\$ 600$ if we restrict to just MODA plans. These figures are very close to the results shown in Figure I, indicating that foregone savings is a good summary measure of welfare loss. Having documented these large welfare losses, the next three sections consider three alternative approaches to mitigating them.

\section{SOLUTION 1: PROMOTING CHOICE}

One approach to reducing choice inconsistencies is to fight inertia through promoting plan choice. To the extent that foregone savings arises from inertia, then promoting individuals to actively choose can reduce choice inconsistencies. Active decisions are not necessarily betterthey require time-investments on the part of the chooser and there is no guarantee individuals will choose well (Carrol et al, 2009). Existing work demonstrates that forcing individuals to choose actively can enhance participation and adherence over opt-in mechanisms (Keller et al, 2011); more generally however, the effectiveness of active choice mechanisms hinges critically on whether active choosers choose well.

One measure of the impact of promoting choice is to compare the choices of switchers to inertial consumers. This captures the effect of choice promotion under the assumption that the inertial consumers would choose as well as those actively choosing. One issue with this comparison is that switchers may be different than inertial consumers; for example, it is likely that 
those that switch are the ones who would benefit the most from switching (as confirmed in Ho et al, 2015; Abaluck and Gruber 2016).

We therefore also exploit an interesting feature of our setup: that some individuals are forced to switch when their district discontinues a plan offering. ${ }^{14}$ This allows us to distinguish between those who actively switch (choosing a new plan even though their old plan was still available) to those who are forced to switch (who no longer have a choice of their old plan). Active switchers are likely those who would benefit the most, while forced switchers may be more representative of what would happen if everyone were forced to choose a new plan. Policies to promote switching would likely range from subtle nudges to forced reassignment, so these estimates can potentially bound the gains from such policies.

To study these phenomena, we turn to a linear regression model of total costs and foregone savings of the form:

$$
y_{i t}=\gamma_{0}+\gamma_{1} F_{i t}+\gamma_{2} A_{i t}+\gamma_{3} I_{i t}+x_{i t} \delta+e_{i t}
$$

where $F_{i t}$ is an indicator for forced switching, $A_{i t}$ is an indicator for active switching, and $I_{i t}$ is an indicator for inertia (choosing the same plan as the previous year). The omitted group is those who are new enrollees, so the coefficients indicate the foregone savings of each group relative to new enrollees; $49 \%$ of the sample is inertial, $17.2 \%$ actively switched, and $12.4 \%$ were forced to switch. All specifications include as controls dummies for sex, age and expenditure $\mathrm{x}$ tier cell as well as dummies for choice set $\mathrm{x}$ tier $\mathrm{x}$ year, meaning that the coefficients are identified by comparing new and returning beneficiaries within a given choice set $\mathrm{x}$ tier $\mathrm{x}$ year cell. ${ }^{15} \mathrm{We}$ are

\footnotetext{
${ }^{14}$ We perform a similar exercise in the setting of prescription drug plans in Abaluck and Gruber (2016), although in that case the fraction of forced switchers was substantially smaller.

${ }^{15}$ In this specification, the reduced form effects of switching relative to baseline are defined in such a way that they include any effects of experience - both switching and inertial beneficiaries will always have some experience in the market relative to new beneficiaries. In Abaluck and Gruber (2016), we estimate a structural model which separately identifies how the quality of choices of prescription drugs plans varies over time due to learning from direct
} 
primarily interested in the savings of switchers relative to inertial enrollees - specifically, if some enrollees who are currently inertial were "nudged" into switching, would we expect this to lead to lower foregone savings?

The results of this model are shown in Table IV, for all plans, and for MODA only. For all plans, we find that inertial consumers are insignificantly different from new entrants with respect to foregone savings; for MODA only, we find that inertial consumers have significantly higher foregone savings than new entrants, but the difference is small ( $\$ 62$ for the year). Most importantly for our current purposes, across all plans, both active and forced switchers do worse than new entrants; across MODA plans, active switchers do slightly better, but forced switchers do much worse.

This conclusion can be confirmed by looking at the natural experiment provided by open enrollment in 2013. As described below, in that year individuals were forced to reenroll in a set of renamed insurance plans, rather than being defaulted into their plan from the previous year. This is a typical type of active choice intervention that has been proposed to increase choice quality. In fact, however, we find that foregone savings are no smaller on average in 2013 than in other years, confirming that promotion of choice is not enough to improve choice quality (albeit based only on a time series pattern).

The major takeaway from these results is that promoting switching is unlikely to have an important effect in reducing choice inconsistencies. Even in the best case, which is that individuals choose as well as active switchers in the MODA only regression, the reduction in foregone savings

experience, what we call "cohort learning" at the population level, and changes in the degree of inertia over time. Our primary goal here is instead to understand whether, among returning beneficiaries, more would have saved money had they been induced to switch. 
is a paltry $\$ 25$. One reason for this may be a lack of information as to the benefits of switching. We investigate this with our next potential solution.

\section{SOLUTION II: INFORMATION INTERVENTION}

The results so far suggest that beneficiaries are leaving money on the table by not choosing lower cost plans. This raises the question - can we induce consumers to choose differently if we inform them of the possible savings? To investigate, we partnered with OEBB and Truven Healthcare to conduct an "informed enrollment" experiment in which beneficiaries in some districts were randomly given access to a tool that provided information about how total costs vary across plans given their claims history. An unplanned feature of this experiment was that - for a variety of reasons we document below - some beneficiaries received inaccurate information. We can thus ask both whether the experiment altered choices and also whether the quality of the recommendation mattered for its effectiveness. This allows us to characterize both what was in practice achievable and what is possible given a perfectly accurate information intervention.

In fall 2012, due to concerns over uninformed choice by OEBB employees, the state contracted with Truven Health Analytics to provide a decision support tool to employees so that they could make more informed plan selections. This tool provides an online platform through which employees are presented information on the premiums and out of pocket costs of their

alternative plan options. Appendix Figures 1-6 show screenshots of the relevant pages of the decision support tool from 2013.

The tool uses an employees' health care claims (and claims of any beneficiaries) from the prior year to categorize beneficiaries into "Health Care Levels" of Low, Medium Low, Medium, Medium High, and High. Beneficiaries could also add dependents, add major health care services, or adjust their categorization. Beneficiaries then entered their district's contributions to premiums, 
and the tool presented an ordered list of the three lowest predicted total cost plans (premiums + out of pocket cost sharing). Predicted total costs, premiums, and predicted out of pockets were displayed in separate columns. The lowest cost plan was marked with a star and noted as "plan option with lowest estimated total cost.”

At our urging, OEBB decided to randomize the roll-out of this new decision support tool. Districts were randomly divided into two groups, with employees in half the districts receiving a notification of access to the tool when they entered the OEBB website to re-enroll in insurance.

When the tool was introduced in fall 2012 it had very little enrollment. This was partly due to technical difficulties which required separate sign-ons for enrollment and for using the decision support tool, as well as the fact that employees who chose to passively reenroll could do so easily without ever interacting with the tool. In the end only $8 \%$ of the eligible employees used the tool when it was available.

As a result, for fall 2013, OEBB re-ran the experiment making several changes. First, as documented in Table I, the set of available health insurance plans was changed, with non-trivial changes to many plans and a non-obvious crosswalk between old and new plans. Second, OEBB employees were forced to re-enroll through the OEBB website, where there was a seamless signon to the decision support tool. As a result, $60 \%$ of treatment arm enrollees logged into the Truven tool for this second open enrollment period and $36 \%$ of treatment arm enrollees received a recommendation, with the other $24 \%$ exiting the tool before getting a recommendation.

We start by evaluating the overall effectiveness of the recommendation. Table $\mathrm{V}$ shows that our results are roughly balanced across treatment and control groups. Prior medical expenditures, total costs (premiums plus out of pocket costs), and demographics are all 
insignificantly different. The prior year number of plans is marginally significantly larger in the treatment group than the control group

Table VI presents the results for treatment versus control districts for foregone savings, for our perfect backcast, rational expectations, and perfect foresight models of expected costs. To deal with any concerns about balance and to increase power, we report results in terms of the change in foregone savings from the prior year.

Foregone savings increased in both the treatment and the control group from 2012 to 2013. Foregone savings did increase by less in the treatment group, but the $\$ 50$ to $\$ 100$ difference is not statistically significant.

There are three reasons we might not see the tool leading to substantially lower costs. The first is that individuals may have not made use of the tool. As noted above, only about one-third of enrollees made it all the way to the tool's recommendation, which is striking given the forced reenrollment and seamless integration of the tool.

The second is that individuals may not follow the tool's recommendation. A limitation in addressing this question is that we do not observe what the recommendation would have been in the control group. We therefore first estimate the choice model in Table III in the treatment sample only with a dummy inserted for the recommended plan. This asks, controlling for observables: were beneficiaries more likely to choose the recommended plan? In the MODA only rational expectations model, among those treatments who received a recommendation, $33.4 \%$ ended up choosing the recommended plan. We estimate that beneficiaries were 8.1 percentage points more likely to choose the recommended plan conditional on receiving the recommendation (implying that 25.3 percent would have chosen the recommended plan without the recommendation). Since 
$36 \%$ of the treatment group received a recommendation, this implies that beneficiaries in the treatment group were 2.9 percentage points more likely to choose recommended plans.

This estimate overstates the effect of the recommendation if individuals were more likely to choose recommended plans than the model predicts based on observable factors absent the intervention. To address this point, we estimate an "IV" specification which compares plans which are predicted to be recommended in the control and treatment groups. We first estimate an auxiliary model to determine what characteristics predict whether a plan will be recommended and then asks whether choices are more sensitive to the probability of recommendation in the treatment group. ${ }^{16}$ In this specification, we find that the probability of choosing a recommended plan in the treatment group is 1.1 percentage points higher (t-stat of 5.46 on logit coefficient). Relative to the 2.9 percentage points obtained in the OLS model, this suggests that about two-thirds of the OLS effect is due to the fact that the recommended plan would have been chosen anyway. In both cases, consumers do appear to have responded to the recommendation but the response is extremely small.

The third reason for a small effect of the recommendation may be that the recommendations themselves were flawed. The recommendation can go awry in two ways. First, a feature of our particular application is that the beneficiary is asked to provide the amount that their employer contributes. If this is entered incorrectly then it could lead directly to a poor recommendation. Second, even given correct information, this particular tool might miscalculate their out of pocket costs because it can only imperfectly replicate the complicated plan benefit rules. For example, while the tool allowed different procedures to have different coinsurances, it was only able to allow

\footnotetext{
${ }^{16}$ In the auxiliary model, limited only to those beneficiaries in the treatment group with a recommendation, we estimate a conditional logit model of whether a plan was recommended as a function of calculated out of pocket costs (created via the perfect backcast version of our calculator, which most closely resembles the IE tool methodology) gross premium, residual premium, and tier*plan dummies.
} 
for a single "copay" amount across all plan services. Since many plans offer widely varying copays, an approximate solution was to pick the coinsurance amount that would on average match observed copays - but this necessarily introduces error into the estimation of out of pocket costs.

We can examine the impact of this problem by comparing the results of the tool recommendations to our more accurate internal calculator, which both uses correct contribution amounts from districts and more comprehensively maps the specific cost sharing rules of the OEBB plans. Of course, our results may not be perfect either, but substantial differences at least offer a suggestion of errors in the recommendation tool. And we do find substantial differences. We estimate that for $61 \%$ of those with a recommended plan, the recommended plan was not in fact the lowest cost plan according to our calculator. If individuals had properly specified their district contributions, but the flaws in the out of pocket cost calculation remained, then for $46 \%$ of the sample the recommended plan would have differed from our recommendation; doing the opposite calculation, for $32 \%$ of the sample the recommended plan would have been different. In other words, while fixing both errors would (by definition) have led to the same recommendation as our calculator, either error alone causes a substantial fraction of recommendations to go awry.

The fact that some consumers received potentially misleading information raises an important question - do we find that consumers are more responsive to more accurate information, and would better recommendations have had a larger impact? Our calculator performs better at replicating out of pocket costs for the actually chosen plan; we cannot know with certainty that our calculator's recommendations are better for alternative plans, but agreement between the two calculators is likely a signal that the recommendation from the Truven tool is correct. A simple reduced form way of investigating this question is therefore to run a linear probability model where we regress choice probabilities on the recommendation dummy interacted with quintiles of 
foregone savings for the recommended plan (e.g. the error in the recommended plan relative to our more accurate calculator). Plans in the first quintile have foregone savings of 0 (they are the lowest cost plan according to our calculator), while plans in the $5^{\text {th }}$ quintile have foregone savings of $\$ 2,778$ (they are far from lowest cost!). Figure II shows the results - beneficiaries were far more likely to follow the recommendation if the plan the tool deemed lowest cost was also lowest cost according to our calculator. In the $1^{\text {st }}$ quintile, the recommendation increased the choice probability by 17.3 percentage points (conditional on receiving a recommendation, while in the $5^{\text {th }}$ quintile the recommendation increase this probability by 4 percentage points. These results suggest that had the information intervention been perfectly accurate (a standard which is in practice hard to achieve), we would have seen a 17.3 percentage point increase in the probability of choosing the recommended plan amongst people who received a recommendation, or roughly 2 times as large as the measured effect of the recommendation.

To summarize, we can decompose the "failure" of the information intervention. Total per capita foregone savings for the treatment group were $\$ 1,223$ - this is what would have been saved had all recommendations been perfect and all beneficiaries followed the recommendation. If the recommendations of the tool had been perfect, and individuals had responded to this information as indicated by the model above, then foregone savings would have fallen by $\$ 212$. Therefore, the major problem facing this tool was a lack of attention paid to the recommendations and a lack of responsiveness even to high quality information. Absent these, information interventions do not appear to significantly reduce foregone savings.

\section{SOLUTION 3: RESTRICTING THE CHOICE SET}

Given that neither more aggressive plan switching nor an information intervention appear to significantly improve the quality of choices, we consider a third, stronger intervention: 
restructuring the choice architecture by limiting the number of options available to individuals who are choosing plans. We do so by reporting reduced form results analyzing how welfare varies with the number of available plans.

As noted in the introduction, a common problem with analyzing the welfare implications of choice set variation is that it can affect both the supply and demand sides of the market. This problem is mitigated in our context because the supply side is fixed with respect to any individual district. So when districts vary the number of choices facing enrollees, this has no impact on the prices that will be paid by these enrollees, allowing us to isolate the demand side impacts of choice set size variation in our context.

Figure IIIA and IIIB show foregone savings by choice set size, first for all plans and then for OMED/MODA only, and for all three models of expectations. While we find substantial foregone savings in each case, there is a significant increase with choice set size. Considering all plans, overspending increases from $\$ 235-\$ 300$ in choice sets of 2 plans, to $\$ 1,650-\$ 1,870$ in choice sets of 10 plans, depending on the out of pocket model. Restricting to only MODA plans to eliminate concerns of unobserved but valued insurer characteristics, overspending is still substantial and increasing with choice set size, more than tripling from choice sets with 2 MODA plans to those with 8 MODA plans.

While suggestive, these results do not speak to the welfare consequences of changing choice set size, since foregone savings may increase even if the plan in which beneficiaries actually end up enrolled is no worse, simply because the best available plan is cheaper in larger choice sets. Additionally, many other factors may differ across districts with different numbers of plan choices. To address this point we turn to a reduced form model of total costs as a function of choice set size and a rich set of covariates. While the fact that foregone savings is larger is one measure of 
the quality of choices, total costs in the plan in which beneficiaries are actually enrolled is a more appropriate welfare measure. ${ }^{17}$ The distinction between total costs and foregone savings was irrelevant when we considered interventions which changed only the chosen plan (such as inducing switching or providing information); it is relevant here because changing choice set size changes both the chosen plan and the best available plan.

We start by constructing a dataset which consists of just the chosen plan for each beneficiary and estimating the coefficients on dummies for the number of plans controlling for other covariates. Specifically, we estimate the equation:

$$
u_{i t r}^{N}=\xi_{J}+x_{i t} \gamma+\xi_{d, r}+\xi_{t, e(i)}+\epsilon_{i t r}
$$

where $u_{i t r}^{N}$ are total costs in the chosen plan, $\xi_{J}$ are the coefficients of interest (the dummies for the number of plans), $x_{i t}$ are controls which include the subsidy amount and beneficiary experience, $\xi_{d, r}$ includes choice set $(d) \mathrm{x}$ tier $(r)$ fixed effects, and $\xi_{t, e(i)}$ includes year $\mathrm{x}$ decile of individual expenditure $(e(i))$ fixed effects. The resulting coefficient measures how total costs vary as the number of plans vary within a choice set over time - holding fixed individual expenditure, subsidy amount and other factors which might impact total costs and foregone savings. We omit the fixed effect for choice sets with 2 plans (the smallest observed choice sets); thus, the estimated plan size effects are all defined relative to choice sets with 2 plans.

Column 1 of Table VII shows the results of this regression with foregone savings on the left hand side. The results are quite close to Figure II. Column 2 reports the results with total costs on the left hand side. While not monotonic, after partialling out covariates, the basic pattern in Figure II remains - choice sets with more plans not only lead to higher foregone savings, but higher total costs in the plan in which beneficiaries actually enroll. Therefore, smaller choice sets do

\footnotetext{
${ }^{17}$ As noted above, supplementing our total cost measure to account for variance has little impact on the results.
} 
appear to be associated with higher quality choices. The differences are quite large relative to the other interventions discussed above; in a choice set of eight relative to a choice set of 2 , foregone savings are higher by $\$ 942$ and total costs are higher by $\$ 677$. Therefore, unlike with promoting switching or providing intervention, limiting choice set size, in our context, appears to hold the promise to substantially improve choice quality.

\section{Aggregate vs. Idiosyncratic Components}

While informative, the reduced form results above do not allow us to distinguish (a) how the nature of the choice set changes with choice set size from (b) how the quality of choices from a given choice set changes with choice set size. We therefore turn next to a structural model that allows us to understand more generally under what conditions larger choice sets might lead to better or worse choices. To do so, we derive an approximation to the choice model above that makes clear the contribution of aggregate and idiosyncratic components. This approximation will help us study how welfare varies as a function of a small number of sufficient statistics summarizing the existing choice set - including the number of plans - and the quality of choices. This model is - as far as we know - the first to formalize the trade-off in choice architecture between the benefits of additional choices due to consumer heterogeneity and the potential costs if marginal plans in larger choice sets are worse on average. In a setting with choice inconsistencies, the latter costs can potentially exceed the benefits. ${ }^{18}$

An auxiliary purpose of the model is to study how our inferences about welfare drawn using only market share data compare to those we would make using individual level claims data matched to individual choices. By decomposing welfare into an aggregate and individual

\footnotetext{
${ }^{18}$ This trade-off is implicit in Abaluck and Gruber (2011) and subsequent models, but the explicit treatment here allows us to study not only whether more choices are better in this setting, but to understand what factors determine whether more choices are better in other contexts.
} 
component, the model allows us to study the circumstances in which market share data will be adequate to draw accurate inferences about welfare as well as how market share data might be supplemented with other moments drawn from claims data even if all choices cannot be matched to claims data.

One can compute the expected value of normative utility $u_{i j t}^{N}$ given that beneficiaries choose according to the positive utility function which yields choice probabilities given by $P\left(Y_{i j t}=1\right)$ :

$$
E\left(u_{i j t}^{N}\right)=\sum_{i} u_{i j t}^{N} P\left(Y_{i j t}=1\right)
$$

We now derive an approximation which relates this expression to underlying features of the choice set. To derive this approximation, we make the following assumptions. First, we Taylor expand $P\left(Y_{i j t}=1\right)$ around the choice probabilities evaluated at the plan average-utility, $u_{j t}=E_{j}\left(u_{i j t}\right)$. This gives us a decomposition in which we can separately consider the impact of these plan-average characteristics and the degree of heterogeneity that we observe. The full decomposition is derived in the Appendix. In our estimation results, we find that measured risk aversion is negligible relative to other components of welfare. To simplify the expression reported in the Appendix, we thus set risk aversion to 0 - this has virtually no impact on our results given the small measured degree of risk aversion. Finally, we assume that expected out of pocket costs can be written as: $E(O O P)_{i j t}=v_{i t}+v_{j t}+v_{i j t}$, the sum of an individual specific component, a plan-specific component and an idiosyncratic component which satisfies $\operatorname{var}\left(v_{i j t}\right)=\sigma_{e}^{2}$.

Given these assumptions, we obtain:

$$
E\left(u_{i j t}^{N}\right) \approx E^{*}\left(u_{j t}^{N}\right)+\xi(J) P_{d}\left(E^{*}\left(u_{j t}^{N}\right)-u_{i d t}^{N}\right)-\beta_{2}\left(J_{i}\right) \sigma_{e}^{2} \sum_{j} P_{j}\left(1-P_{j}\right)
$$


where $E^{*}\left(u_{i j t}^{N}\right)$ gives the utility that would result if plans were chosen given only plan-average utility and utility were evaluated only at the plan average utility, $\xi$ is the inertia dummy, $P_{j}$ is the probability plan $j$ is chosen given plan average utility, $u_{i d t}^{N}$ is the utility of the default (baseline) plan, and $\sigma_{e}^{2}$ is as above the degree to which out of pocket costs vary across plans for a given individual.

In other words, the difference between actual realized utility and what utility would be given only the plan average characteristics depends (a) first on the degree of inertia multiplied by whether the inertial plan is better for the individual than the average plan, and (b) second, on the product of the sensitivity to individual heterogeneity $\left(\beta_{2}\left(J_{i}\right)\right)$, the degree to which out of pocket costs vary across individuals for a given plan (after partialling out individual fixed effects), and $\sum_{j} P_{j}\left(1-P_{j}\right)$, which is one minus the "average utility" Herfindahl. In the limiting case in which one plan has average utility far higher than all the other plans (and so the Herfindahl $H=\sum_{j} P_{j}^{2}$ goes to 1 and $\sum_{j} P_{j}\left(1-P_{j}\right)=1-H$ goes to zero) individual heterogeneity doesn't matter much. Alternatively, if many plans have some market share given average utility, then welfare may be substantially larger than implied just by the average utility of plans because, the greater the degree of individual heterogeneity $\left(\sigma_{e}^{2}\right)$ and the more sensitive individuals are to this heterogeneity $\left(\beta_{2}\left(J_{i}\right)\right)$, the more they will benefit from matching to plans that are idiosyncratically good for them.

Note that the first term, $E^{*}\left(u_{j t}^{N}\right)$, is the utility we would calculate if we had only aggregate market shares and could estimate plan average costs (the latter being necessary to compute average normative utility for each plan, which is not implied by the market shares). To compute the remainder of this equation, we would need estimates on the probability of inertia by plan, the sensitivity of choices to out of pocket costs and the variance of the idiosyncratic component of out 
of pocket costs after partialling out individual and plan fixed effects. To the extent that the latter two terms are small, the computation based only on aggregate market share data will be accurate.

We report results using just the number of MODA plans and the rational expectations measure. As previously noted, the columns 1 and 2 of Table VII show that foregone savings and total costs for the chosen plan respectively are increasing in the number of available plans. After partialling out covariates, total costs increase by almost $\$ 700$ as one moves from choice sets with 2 plans to choice sets with 8 plans.

To investigate the causes of this pattern, we re-estimate equation 4 using each of the three terms from equation 6 on the left-hand side. These results are reported in subsequent columns of table VII. Column 2 gives the average cost of the chosen plan, Column 3 gives the sum of the three terms on the RHS of equation 6. Both show the same overall pattern of increasing costs as the choice set gets larger, although the pattern is more muted in our simulation. In other words, the model in equation 6 (column 3) reproduces the basic pattern we see in the actual data (column 2), albeit somewhat muted.

Column 4 reports the value of $E^{*}\left(u_{j t}^{N}\right)$, average utility if consumers chose according to the positive model given the plan-average characteristics of each plan. This column shows that the finding that larger choice sets lead to higher cost choices is due to the fact that the plans in larger choice sets are on average worse. If consumers chose just based on average costs, their total costs in choice sets with 2-3 plans would be $\$ 500$ - $\$ 600$ less than their total costs in choice sets with 78 plans.

Inertia and individual heterogeneity slightly mitigate this but not enough to offset it. As we found in our reduced form investigation, inertia tends to raise costs but accounts for less than 
$\$ 100$ of total costs in all case (column 5), and does not vary much with choice size. That is, inertia tends to further increase total costs, but not by much, and not by any more in larger choice sets.

Individual heterogeneity does to some extent offset the higher costs arising in larger choice sets. As shown in column 6 , the fact that out of pocket costs vary across consumers also tends to reduce costs relative to if consumers paid attention only to aggregate factors and to do so by more in larger choice sets. But this effect is small and is not enough to offset the fact that larger choice sets have more expensive plans - as noted above, column 4 of Table VII shows the average effect of larger choice sets having more expensive plans; column 3 gives the net effect after adding in inertia (column 5) and the benefits of heterogeneity (column 6).

One potential explanations for these findings could be that beneficiaries choose more poorly from larger choice sets, or that there is "choice overload". We investigate this point in Table VIII. Specifically we show the results of varying only the coefficients $\beta(J)$ and $\xi(J)$ to evaluate the impact of choice overload - how does the quality of choices from a given set of supply side plans vary? In contrast to Table VII, each row of table VIII considers all choice sets regardless of the actual number of options; we are varying the demand side parameters to show what costs would be if beneficiaries chose "as if" there were the listed number of plans for that row. The result of this exercise is that we see little variation in choice quality - we find no evidence that choices are systematically worse as the number of plans increase. Compared to Figures IIIA \& IIIB we see relatively little variation - foregone welfare in the all plans column ranges from $\$ 690$ $\$ 940$, while in the MODA only column it ranges from $\$ 520-\$ 720$. This confirms our conclusion that larger choice sets appear to make consumers worse off because the marginal plans added in larger choice sets have higher costs for the average beneficiary as shown in Table VIII and not because consumers choose differently from a given choice set. 
Taken together, the finding from Tables VII and VIII lead to two important conclusions. First, in our context, smaller choice sets lead to beneficiaries being enrolled in lower cost plans because larger choice sets have more plans which are higher cost on average - and individual choices do little to offset this "more dangerous" choice environment. The very small benefits of heterogeneity, relative to the large increase in average costs with choice set size, suggest that a large reduction in choice frictions would be required before heterogeneity could offset the effects of poorer choices. ${ }^{19}$ Second, because aggregate choice set size differences in total cost are not offset by individual heterogeneity, we find that market share data in Oregon would have been enough to draw accurate inferences about total cost and foregone welfare.

\section{VIII: CONCLUSIONS}

Debates over the role of choice in health insurance markets are likely to only grow in the coming years. The exchanges that form the backbone of the ACA are under political attack, and the Republican majority in Congress has stated its preferences for further promoting choice through "premium support" programs for Medicare. As a result, it is critical to understand the implications of choice over insurance products, and one of the most important elements of such understanding is how choice impacts the quality of consumer insurance plan enrollment.

The setting explored in this paper has a number of unique advantages for addressing this question. We have sizeable variation in the nature of choice sets facing otherwise similar individuals, with variation in the number of insurance options, the relative prices of these options, and the individual cost sharing implications of these options. We also have a randomized trial of

\footnotetext{
${ }^{19}$ For example, consider the case where the sensitivity to out of pocket costs were increased by a factor of 3 -- meaning that, in the rational expectations model, the sensitivity to individualized features of costs were as large as the sensitivity to premiums. Applying equation (6), this would multiply the benefits of heterogeneity in Table VII by a factor of 3 , which would close just 5-10\% of the gap between the smallest and largest choice sets.
} 
decision support software which allows us to assess the impact of providing (noisy) information around insurance choices. And we have broad data on insurance choice sets, medical claims, and use of the decision support tool.

We use these data to first document sizeable choice inconsistencies. Our finding confirms evidence from Handel (2013) and Bhargava et al. (2015) that choices are inconsistent in the broader insurance context, as well as a series of studies which document such inconsistencies in the choice over prescription drug plans. The dollars at stake are sizeable; even among plans which are identical in all aspects other than financial coverage characteristics, foregone savings is in the range of $\$ 500-\$ 600$ per year.

We then turn to a novel exploration of three approaches to addressing these choice inconsistencies. We find that interventions that promote more active choice across plans are unlikely to improve the quality of choices. And we find disappointingly small effects of an information intervention. These effects appear to be partly due to low quality recommendations, but mostly due to the fact that individuals don't pay attention to even high quality recommendations.

On the other hand, we find that insurance costs are much lower in smaller than in larger choice sets; since pricing is set at the state and not district level, this effect arises solely through choice differences and not competitive effects. This effect appears to arise from variation in the quality of choices that are offered by plan administrators as choice set sizes grow, and the fact that poorer choices on average are not offset by individuals through better decision making. Indeed, our findings suggest that aggregate data on the total costs of decision sets are sufficient to measure their quality, due to the very small offsetting individual responses. 
A key question raised by our results is the generalizability of the finding that marginal plans in larger choice sets are worse. We might expect this pattern to exist in a setting like Oregon where benefits managers pick how many plans to offer from a common superset of plans. The "best" plans will be chosen in all cases and worse plans will only be added by those benefit managers with an inclination to be more inclusive even if this means including plans that are worse on average for most people. If the set of plans is determined endogenously by plan entry as in the ACA, it is unclear whether marginal plans which choose to exit in large choice sets will be lower or higher cost for the average beneficiary. This is an important topic for future research. 


\section{APPENDIX}

Deriving the Decomposition into Aggregate and Idiosyncratic Components

We suppress the $t$ subscript throughout - each $(i, t)$ is modeled as a separate choice. We additionally normalize $\beta_{0}$, the coefficient on gross premiums, to -1 . We use the subscript $c$ to denote choice sets defined by district $\mathrm{x}$ tier - premiums are constant within these choice sets.

Beneficiaries choose as if their utility from plan $j$ is given by:

$$
u_{i j c}=u_{j c}+\xi_{i, j=d}+v_{i j} \alpha+\varepsilon_{i j}
$$

where $\varepsilon_{i j}$ is i.i.d. extreme value. $u_{j c}$ is (perceived) plan average utility, $\xi_{i, j=d}$ is an inertia dummy and $v_{i j}$ are individualized observable characteristics of plans such as the mean and variance of out of pocket costs. Within a set of beneficiaries with the same default plan, $\xi_{i, j=d}$ can be collapsed into $u_{j}$ (since it is 1 or 0 for any given plan). To connect explicitly to the model in the text, we have: $u_{j c}=-$ Gross premium prc $_{j}+\beta_{1}(J)$ Residualized premium prc $_{j}+d_{j}$. We write normative utility as $u_{i j}^{N}=u_{j c}^{N}+v_{i j} \alpha^{N}$. (Note that misweighting of residual premiums for example would lead to $u_{j c} \neq u_{j c}^{N}$ ). In general, we also have $\alpha^{N} \neq \alpha$ - the coefficient on out of pocket costs in normative utility is -1 (given the premium normalization), whereas the coefficient in positive utility may be less than 1 . Below, we further suppress the subscript $c$ and write $u_{j}$ to denote the average perceived utility from plan $j$ within each choice set and $u$ (shorthand for $u_{c}$ ) the vector of these plan average perceived utilities.

Expected welfare is given by:

$$
E_{i}\left(u_{i j}^{N}\right)=E_{i} \sum_{j} u_{i j}^{N} P\left(Y_{i j}=1\right)
$$

where $Y_{i j}$ is an indicator for whether beneficiary $i$ chooses plan $j$. In the full model, we have: 


$$
P\left(Y_{i j}=1\right)=\frac{1}{1+\sum_{k \neq j} \exp \left(u_{i k}-u_{i j}\right)}
$$

To make possible tractable analytical results, we make a few additional assumptions. First, we assume that we can write: $v_{i j}=v_{i}+e_{i j}$ where $v_{i}$ and $e_{i j}$ are independent, $\operatorname{var}\left(v_{i}\right)=\sigma_{i}^{2}$ (the variance of the average deviation of OOP costs) and $\operatorname{var}\left(e_{i j}\right)=\sigma_{e}^{2}$. We do a multi-dimensional Taylor expansion of equation 3 around the point $u_{i k}=u_{k}$ for all $k$.

$$
\begin{aligned}
\text { Let } f_{j}\left(u_{i}\right)= & \frac{1}{1+\sum_{k \neq j} \exp \left(u_{i k}-u_{i j}\right)} \text {. Note that: } \\
& \frac{\partial f_{j}}{\partial u_{i j}}(u)=\frac{\sum_{k \neq j} \exp \left(u_{k}-u_{j}\right)}{\left[1+\sum_{k \neq j} \exp \left(u_{k}-u_{j}\right)\right]^{2}}=P_{j}\left(1-P_{j}\right)
\end{aligned}
$$

and

$$
\frac{\partial f_{j}}{\partial u_{i k}}(u)=-\frac{\exp \left(u_{k}-u_{j}\right)}{\left[1+\sum_{k \neq j} \exp \left(u_{k}-u_{j}\right)\right]^{2}}=-P_{j} P_{k}
$$

Let $l$ index the elements of $v$ and $\alpha$ for a given individual-plan. Thus, our Taylor-expansion is given by:

$$
\begin{aligned}
P\left(Y_{i j}=1\right) \approx & \frac{1}{1+\sum_{k \neq j} \exp \left(u_{k}-u_{j}\right)} \\
& +\sum_{k} \frac{\partial f_{j}\left(u_{i}\right)}{\partial u_{i k}}\left(u_{i k}-u_{k}\right) \frac{1}{1+\sum_{k \neq j} \exp \left(u_{k}-u_{j}\right)} \\
& +\sum_{k} \frac{\partial f_{j}(u)}{\partial u_{i k}} \xi_{i, k=d}+\sum_{l} \sum_{k} \frac{\partial f_{j}(u)}{\partial u_{i k}} \alpha_{l} v_{i k l}
\end{aligned}
$$

Then equation 2 gives:

$$
E_{i}\left(u_{i j}^{N}\right)=E_{i} \sum_{j} u_{i j}^{N}\left[\frac{1}{1+\sum_{k \neq j} \exp \left(u_{k}-u_{j}\right)}+\sum_{k} \frac{\partial f_{j}(u)}{\partial u_{i k}} \xi_{i, k=d}+\sum_{l} \sum_{k} \frac{\partial f_{j}(u)}{\partial u_{i k}} \alpha_{l} v_{i k l}\right]
$$




$$
\begin{aligned}
& =\sum_{j}\left[u_{j}^{N} \frac{1}{1+\sum_{k \neq j} \exp \left(u_{k}-u_{j}\right)}+u_{j}^{N} E_{i} \sum_{k} \frac{\partial f_{j}(u)}{\partial u_{i k}} \xi_{i, k=d}\right] \\
& +E_{i} \sum_{j} \sum_{l^{\prime}} \alpha_{l}^{N} v_{i j l^{\prime}} \sum_{l} \sum_{k} \frac{\partial f_{j}(u)}{\partial u_{i k}} \alpha_{l} v_{i k l} \\
& =E^{*}(u)+\sum_{j} u_{j}^{N} E_{i} \frac{\partial f_{j}(u)}{\partial u_{i d(i)}} \xi+E_{i} \sum_{j} \sum_{l^{\prime}} \sum_{l} \sum_{k} \frac{\partial f_{j}(u)}{\partial u_{i k}} \alpha_{l}^{N} \alpha_{l} v_{i k l} v_{i j l^{\prime}} \\
& =E^{*}(u)+\xi\left[-u_{d}^{N} P_{d}\left(1-P_{d}\right)+P_{d} \sum_{j \neq d} u_{j}^{N} P_{j}\right]+\sum_{j} P_{j}\left(1-P_{j}\right) \sum_{l^{\prime}} \sum_{l} \alpha_{l}^{N} \alpha_{l} E_{i}\left(v_{i j l} v_{i j l^{\prime}}\right) \\
& -\sum_{j} \sum_{k \neq j} P_{j} P_{k} \sum_{l^{\prime}} \sum_{l} \alpha_{l}^{N} \alpha_{l} E_{i}\left(v_{i j l} v_{i k l^{\prime}}\right) \\
& =E^{*}(u)+\xi P_{d}\left[E^{*}(u)-u_{d}^{N}\right]+\sum_{j} P_{j}\left(1-P_{j}\right) \sum_{l^{\prime}} \sum_{l} \alpha_{l}^{N} \alpha_{l} E_{i}\left(v_{i j l} v_{i j l^{\prime}}\right) \\
& -\sum_{j} \sum_{k \neq j} P_{j} P_{k} \sum_{l^{\prime}} \sum_{l} \alpha_{l}^{N} \alpha_{l} E_{i}\left(v_{i j l} v_{i k l^{\prime}}\right)
\end{aligned}
$$

where $E^{*}(u)$ is expected welfare given that you choose as if you know only average utility for each plan $u_{j}$ (and not the individual component $v_{i j}$ ) and $P_{j}$ is the probability of choosing plan $j$ given that you choose as if you know only average utility for each plan.

If we assume as above that the variance coefficient in normative and positive utility is 0 , then this simplifies to:

$$
E^{*}(u)+\xi P_{d}\left[E^{*}(u)-u_{d}^{N}\right]-\beta_{2}(J) \sigma_{e}^{2} \sum_{j} P_{j}\left(1-P_{j}\right)
$$

which is the equation in the text. 


\section{REFERENCES}

Abaluck, Jason and Jonathan Gruber, "Choice Inconsistencies among the Elderly: Evidence from Plan Choice in the Medicare Part D Program,” American Economic Review, 101(4) (2011), 1180-1210.

Abaluck, Jason and Jonathan Gruber, "Evolving Choice Inconsistencies in Choice of Prescription Drug Insurance," American Economic Review, 106(8) (2016), 2145-2184.

Abaluck, Jason and Jonathan Gruber, "The Robustness of Checks for Consumer Choice Inconsistencies: Reply to Ketcham, Kuminoff and Powers," American Economic Review, forthcoming.

Bhargava, Saurabh, George Loewenstein, and Justin Sydnor, "Do Individuals Make Sensible Health Insurance Decisions? Evidence from a Menu with Dominated Options," NBER Working Paper No. 21160, 2015.

Brown, Jason, Mark Duggan, Ilyana Kuziemko, and William Woolston, "How does risk selection respond to risk adjustment? Evidence from the Medicare Advantage program," American Economic Review, 104(10) (2014), 3335-3364.

Carroll, Gabriel D., James J. Choi, David Laibson, Brigitte C. Madrian, Andrew Metrick, “Optimal Defaults and Active Decisions," The Quarterly Journal of Economics, 124(4) (2009), 16391674.

Cutler, David M., and Sarah J. Reber, "Paying for Health Insurance: The Trade-Off between Competition and Adverse Selection," The Quarterly Journal of Economics, 113(2) (1998), 433-466.

Choi, James, David Laibson, Brigitte Madrian, Andrew Metrick, "Defined Contribution Pensions: Plan Rules, Participant Decisions, and the Path of Least Resistance," Tax Policy and the Economy, (2002), 16:67-114.

Dafny, Leemore S., Jonathan Gruber, and Christopher Ody, "More Insurers, Lower Premiums: Evidence from Initial Pricing in the Health Insurance Marketplaces," American Journal of Health Economics 1, no. 1 (Winter) (2015), 53-81.

Dafny, Leemore S., Mark Duggan, and Subramaniam Ramanarayanan, "Paying a Premium on Your Premium? Consolidation in the U.S. Health Insurance Industry," American Economic Review 102, no. 2 (April) (2012), 1161-1185.

Einav, Liran, Amy Finkelstein, and Jonathan Levin, "Beyond Testing: Empirical Models of Insurance Markets,” Annual Review of Economics, 2(1) (2010), 311-336.

Ericson, Keith, Jon Kingsdale, Timothy J Payton, and Adam Sacarny, "Information Frictions in Health Insurance Marketplaces: Evidence from a Randomized Field Experiment." Working Paper. https://ashecon.confex.com/ashecon/2016/webprogram/Paper4452.html (2016), Accessed 20 October 2016. 
Handel, Benjamin R., "Adverse selection and inertia in health insurance markets: When nudging hurts.” The American Economic Review, 103(7) (2013), 2643-2682.

Handel, Benjamin R, and Jonathan T Kolstad, "Health Insurance for "Humans": Information Frictions, Plan Choice, and Consumer Welfare.” American Economic Review, 105(8) (2015), 2449-2500.

Heiss, Florian, Adam Leive, Daniel McFadden, and Joachim Winter, "Plan selection in Medicare Part D: Evidence from administrative data," Journal of Health Economics. 32(6) (2013), 1325-1344.

Friedman, Abigail S, and Richard Frank., "Using Behavioral Economics to Improve Plan Choice in Medicare: A Randomized Experiment.” Working Paper. https://ashecon.confex.com/ ashecon/2016/webprogram/Paper4742.html (2016), Accessed 20 October 2016.

Geruso, Michael and Thomas G. McGuire, "Tradeoffs in the design of health plan payment systems: Fit, power and balance," Journal of Health Economics, 47 (2016), 1-19.

Geruso, Michael and Timothy Layton "Upcoding: Evidence from Medicare on Squishy Risk Adjustment,” NBER Working Paper No. 21222, (2015).

Grubb, Michael D. and Matthew Osborne, "Cellular Service Demand: Biased Beliefs, Learning, and Bill Shock," American Economic Review, 105(1) (2015), 234-71.

Glazer, Jacob, and Thomas G McGuire, "Optimal risk adjustment in markets with adverse selection: an application to managed care," The American Economic Review, 90(4) (2000), 1055-1071.

Ho, Kate, Joseph Hogan, and Fiona Scott Morton, "The impact of consumer inattention on insurer pricing in the Medicare Part D program”, NBER Working Paper No. w21028, (2015).

Iyengar, Sheena S., and Emir Kamenica, "Choice proliferation, simplicity seeking, and asset allocation," Journal of Public Economics 94 (2010), 530-539.

Jacobson, Gretchen, Anthony Damico, and Tricia Neuman, Kaiser Family Foundation, "What's in and What's Out? Medicare Advantage Market Entries and Exits for 2016," 13 October 2015, http://kff.org/report-section/whats-in-and-whats-out-medicare-advantage-marketentries-and-exits-for-2016-appendix/ Accessed 8 September 2016.

Jacobson, Gretchen, Marsha Gold, Anthony Damico, Tricia Neuman, and Giselle Casillas, Kaiser Family Foundation, "Medicare Advantage 2016 Data Spotlight: Overview of Plan Changes", 03 December 2015, http://kff.org/medicare/issue-brief/medicare-advantage2016-data-spotlight-overview-of-plan-changes/ Accessed 8 September 2016.

Kaiser Family Foundation, "Health Insurance Coverage of the Total Population: 2014," http://kff.org/other/state-indicator/total-population/ Accessed 8 September 2016. 
Kaiser Family Foundation, 2015 Employer Health Benefits Survey, 22 September 2015, http://kff .org/health-costs/report/2015-employer-health-benefits-survey/ Accessed 8 September 2016.

Kaiser Family Foundation, "2016 QHP landscape data,” 29 July 2016, https://www.healthcare .gov/health-plan-information-2016/ Accessed 8 September 2016.

Kaiser Family Foundation. "The Medicare Part D Prescription Drug Benefit". 13 October 2015. http://kff.org/medicare/fact-sheet/the-medicare-prescription-drug-benefit-fact-sheet/

Keller, Punam Anand, Bari Harlam, George Loewenstein, and Kevin G. Volpp, "Enhanced active choice: A new method to motivate behavior change," Journal of Consumer psychology 21, no. 4 (2011), 376-383.

Ketcham, Jonathan D., Claudio Lucarelli, and Christopher Powers. "Paying Attention or Paying Too Much in Medicare Part D.” American Economic Review, 105(1) (2015), 204-233.

Ketcham, Jonathan D., Nicolai V. Kuminoff, and Christopher A. Powers, "Choice Inconsistencies among the Elderly: Evidence from Plan Choice in the Medicare Part D Program: Comment," American Economic Review, forthcoming.

Kling, Jeffrey R., Sendhil Mullainathan, Eldar Shafir, Lee C. Vermeulen, and Marian V. Wrobel, "Comparison Friction: Experimental Evidence from Medicare Drug Plans." The Quarterly Journal of Economics, 127 (1) (2012), 199-235

Newhouse, Joseph P, Mary Price, Jie Huang, J Michael McWilliams, and John Hsu. "Steps to reduce favorable risk selection in Medicare advantage largely succeeded, boding well for health insurance exchanges." Health Affairs, 31(12) (2012), 2618-2628. 
Table I

Plans Available By Year

\begin{tabular}{|c|c|c|c|c|c|c|c|}
\hline Plan & 2008 & 2009 & 2010 & 2011 & 2012 & Plan $^{2}$ & 2013 \\
\hline Kaiser Medical Plan 1 & $\mathrm{Y}$ & Y & $\mathrm{Y}$ & $\mathrm{Y}$ & $\mathrm{Y}$ & Kaiser Medical Plan 1 & $\mathrm{Y}$ \\
\hline Kaiser Medical Plan 2 & Y & Y & - & - & - & Kaiser Medical Plan 2 & - \\
\hline Kaiser Medical Plan 1A & - & Y & $\mathrm{Y}$ & Y & Y & Kaiser Medical Plan 1A & Y \\
\hline ODS Medical Plan 3 & Y & Y & Y & Y & Y & MODA Medical Plan A & Y \\
\hline ODS Medical Plan 4 & Y & Y & Y & Y & Y & MODA Medical Plan B & Y \\
\hline ODS Medical Plan 5 & Y & Y & Y & Y & $\mathrm{Y}$ & MODA Medical Plan C & Y \\
\hline ODS Medical Plan 6 & $\mathrm{Y}$ & Y & $\mathrm{Y}$ & Y & Y & MODA Medical Plan D & Y \\
\hline ODS Medical Plan 7 & Y & Y & Y & Y & Y & MODA Medical Plan E & Y \\
\hline ODS Medical Plan 8 & Y & Y & Y & Y & Y & MODA Medical Plan F & Y \\
\hline ODS Medical Plan 9 & Y & Y & Y & Y & Y & MODA Medical Plan G & Y \\
\hline Providence Medical Plan 1 & Y & Y & - & - & - & MODA Medical Plan H & Y \\
\hline Providence Medical Plan 2 & Y & Y & Y & Y & - & & \\
\hline Providence Medical Plan 1A & - & Y & - & - & - & & \\
\hline Providence Medical Plan 2A & - & - & Y & Y & - & & \\
\hline
\end{tabular}

Notes:

1. "Y" indicates that a plan was offered in at least one district and "_" indicates that a plan was not offered in any districts in a given year.

2. Between 2012 and 2013 enrollment, ODS changed their name to MODA Health. Plans offered prior to 2013 and in 2013 are listed alphabetically, plans listed in the same row before and after the name change are not necessarily equivalent. In our analysis of plan choices in 2013 we consider whether plans introduced in 2013 were simply renamed or offered qualitatively different benefits. 
Table II

Number of Policy Holders With Each Choice Set Size By Year

\begin{tabular}{lccccccc}
\hline Choice Set Size & 2008 & 2009 & 2010 & 2011 & 2012 & 2013 & All Years \\
\hline 2 & 4,464 & 1,378 & 222 & 30 & 1,196 & 26 & 7,316 \\
3 & 22,176 & 6,252 & 5,148 & 9,132 & 5,589 & 6,429 & 54,726 \\
4 & 112,096 & 142,732 & 141,212 & 128,960 & 41,492 & 23,788 & 590,280 \\
5 & 0 & 0 & 0 & 0 & 32,940 & 31,580 & 64,520 \\
6 & 0 & 0 & 0 & 0 & 22,362 & 12,132 & 34,494 \\
7 & 0 & 0 & 0 & 0 & 9,485 & 8,414 & 17,899 \\
8 & 0 & 0 & 0 & 0 & 8,736 & 35,760 & 44,496 \\
9 & 0 & 0 & 0 & 0 & 80,541 & 3,753 & 84,294 \\
10 & 0 & 0 & 0 & 0 & 0 & 91,570 & 91,570 \\
\hline
\end{tabular}


Table III

Logit Models of Plan Choice

\begin{tabular}{|c|c|c|c|c|c|c|}
\hline & \multicolumn{2}{|c|}{ Perfect Backcast } & \multicolumn{2}{|c|}{ Perfect Forecast } & \multicolumn{2}{|c|}{ Rational Expectations 1} \\
\hline & All Plans & $\begin{array}{l}\text { MODA } \\
\text { Only }\end{array}$ & All Plans & $\begin{array}{l}\text { MODA } \\
\text { Only }\end{array}$ & All Plans & $\begin{array}{l}\text { MODA } \\
\text { Only }\end{array}$ \\
\hline $\begin{array}{l}\text { Gross Premium } \\
\text { (hundreds) }\end{array}$ & $\begin{array}{l}-0.070 * * * \\
(0.001)\end{array}$ & $\begin{array}{c}-0.079 * * * \\
(0.001)\end{array}$ & $\begin{array}{c}-0.070 * * * \\
(0.001)\end{array}$ & $\begin{array}{c}-0.046^{* * * *} \\
(0.001)\end{array}$ & $\begin{array}{c}-0.070 * * * \\
(0.001)\end{array}$ & $\begin{array}{c}-0.079 * * * \\
(0.001)\end{array}$ \\
\hline $\begin{array}{l}\text { Residual Premium } \\
\text { (hundreds) }\end{array}$ & $\begin{array}{c}-0.025 * * * \\
(0.001)\end{array}$ & $\begin{array}{c}-0.032 * * * \\
(0.001)\end{array}$ & $\begin{array}{c}-0.029 * * * \\
(0.000)\end{array}$ & $\begin{array}{c}-0.002 * * \\
(0.001)\end{array}$ & $\begin{array}{c}-0.026^{* * *} \\
(0.001)\end{array}$ & $\begin{array}{c}-0.032 * * * \\
(0.001)\end{array}$ \\
\hline $\begin{array}{l}\text { Mean OOP costs } \\
\text { (hundreds) }\end{array}$ & $\begin{array}{c}-0.007 * * * \\
(0.001)\end{array}$ & $\begin{array}{c}-0.030 * * * \\
(0.001)\end{array}$ & $\begin{array}{c}-0.005 * * * \\
(0.000)\end{array}$ & $\begin{array}{c}-0.033^{* * * *} \\
(0.001)\end{array}$ & $\begin{array}{c}-0.019 * * * \\
(0.001)\end{array}$ & $\begin{array}{c}-0.038 * * * \\
(0.001)\end{array}$ \\
\hline $\begin{array}{r}\text { Variance OOP costs } \\
\left.\text { (times } 10^{\wedge} 6\right)\end{array}$ & - & - & - & - & $\begin{array}{l}-0.003 \\
(0.005)\end{array}$ & $\begin{array}{c}0.013 \\
(0.009)\end{array}$ \\
\hline Fuzzy Inertia & $\begin{array}{c}1.792 * * * \\
(0.020)\end{array}$ & $\begin{array}{c}1.764 * * * \\
(0.022)\end{array}$ & $\begin{array}{c}1.705^{* * * *} \\
(0.018)\end{array}$ & $\begin{array}{c}1.683 * * * \\
(0.021)\end{array}$ & $\begin{array}{c}1.790 * * * \\
(0.020)\end{array}$ & $\begin{array}{c}1.766^{* * * *} \\
(0.022)\end{array}$ \\
\hline Sharp Inertia & $\begin{array}{c}2.510 * * * \\
(0.009)\end{array}$ & $\begin{array}{c}1.971 * * * \\
(0.009)\end{array}$ & $\begin{array}{c}2.426 * * * \\
(0.008)\end{array}$ & $\begin{array}{c}1.909 * * * \\
(0.009)\end{array}$ & $\begin{array}{c}2.509 * * * \\
(0.009)\end{array}$ & $\begin{array}{c}1.974 * * * \\
(0.009)\end{array}$ \\
\hline $\begin{array}{l}\text { Deductible, in } \\
\text { network } \\
\end{array}$ & $\begin{array}{c}-0.040 * * * \\
(0.001)\end{array}$ & $\begin{array}{c}-0.046 * * * \\
(0.001)\end{array}$ & $\begin{array}{c}-0.044 * * * \\
(0.001)\end{array}$ & $\begin{array}{c}-0.043 * * * \\
(0.001)\end{array}$ & $\begin{array}{c}-0.042 * * * \\
(0.001)\end{array}$ & $\begin{array}{c}-0.045^{* * * *} \\
(0.001)\end{array}$ \\
\hline $\begin{array}{l}\text { Max OOP, in } \\
\text { network }\end{array}$ & $\begin{array}{c}-0.014 * * * \\
(0.000)\end{array}$ & $\begin{array}{c}-0.026 * * * \\
(0.000)\end{array}$ & $\begin{array}{l}-0.017 * * * \\
(0.000)\end{array}$ & $\begin{array}{c}-0.023 * * * \\
(0.000)\end{array}$ & $\begin{array}{c}-0.017 * * * \\
(0.000)\end{array}$ & $\begin{array}{c}-0.028 * * * \\
(0.000)\end{array}$ \\
\hline $\begin{array}{l}\text { PCP copay, in } \\
\text { network } \\
\quad \text { (hundreds) }\end{array}$ & $\begin{array}{c}3.249^{* * *} \\
(0.091)\end{array}$ & $\begin{array}{c}-1.967 * * * \\
(0.131)\end{array}$ & $\begin{array}{c}-3.160 * * * \\
(0.099)\end{array}$ & $\begin{array}{c}-2.697 * * * \\
(0.117)\end{array}$ & $\begin{array}{c}-2.288^{* * * *} \\
(0.113)\end{array}$ & $\begin{array}{c}-1.735^{* * *} \\
(0.131)\end{array}$ \\
\hline $\begin{array}{l}\text { Foregone welfare } \\
\qquad \text { Mean (SD) }\end{array}$ & $\begin{array}{l}1012.40 \\
1476.87\end{array}$ & $\begin{array}{c}591.94 \\
1079.99\end{array}$ & $\begin{array}{l}967.11 \\
1458.36\end{array}$ & $\begin{array}{c}563.57 \\
1062.99\end{array}$ & $\begin{array}{c}940.36 \\
1271.56\end{array}$ & $\begin{array}{c}602.14 \\
1084.65\end{array}$ \\
\hline $\begin{array}{l}\text { Foregone welfare } \\
\text { (no variance) }\end{array}$ & $\begin{array}{l}1012.40 \\
1476.87\end{array}$ & $\begin{array}{c}591.94 \\
1079.99\end{array}$ & $\begin{array}{c}967.11 \\
1458.36\end{array}$ & $\begin{array}{c}563.57 \\
1062.99\end{array}$ & $\begin{array}{c}939.88 \\
1271.40\end{array}$ & $\begin{array}{c}602.74 \\
1082.61\end{array}$ \\
\hline $\begin{array}{l}\text { Percent selecting } \\
\text { cost minimizing plan }\end{array}$ & $35.9 \%$ & $45.6 \%$ & $37.3 \%$ & $47.4 \%$ & $33.4 \%$ & $42.1 \%$ \\
\hline
\end{tabular}

Notes:

1. Rational expectations using regression predicted approach with 2,000 draws.

2. As in Appendix Table 1, we drop beneficiaries with only 1 plan in their choice set. However, for MODA only columns in this table, we do not drop beneficiaries with 1 MODA and 1 or more non-MODA plan, and thus a choice set of 1 when restricting to MODA plans. In Figures I \& II, we do drop such individuals to avoid having observations with mechanically 0 overspending.

3. *** Significant at the 1 percent level. ** Significant at the 5 percent level. * Significant at the 10 percent level. 
Table IV

OLS Models of Switching and Inertia

\begin{tabular}{|c|c|c|}
\hline Sample & All Plans & MODA Only \\
\hline Outcome Variable & Foregone Savings & Foregone Savings \\
\hline \multicolumn{3}{|l|}{ Coefficient (SE) } \\
\hline Forced Switch & $\begin{array}{c}180.9 * * * \\
(17.35)\end{array}$ & $\begin{array}{c}174.7 * * * \\
(15.30)\end{array}$ \\
\hline Active Switch & $\begin{array}{c}61.12 * * * \\
(15.03)\end{array}$ & $\begin{array}{c}-25.28 * \\
(14.11)\end{array}$ \\
\hline Inertia & $\begin{array}{l}-11.26 \\
(13.99)\end{array}$ & $\begin{array}{c}61.80 * * * \\
(13.25)\end{array}$ \\
\hline
\end{tabular}

Notes:

1. All models also have controls for gender, age dummies, and expenditure*tier interactions for 20 quantiles of expenditure in the prior year and 4 tiers (employee only, employee and child, employee and spouse, family), and include fixed effects for the interaction of choice set, tier, and year.

2. *** Significant at the 1 percent level. ** Significant at the 5 percent level. * Significant at the 10 percent level. 
Table V

Balance Test

\begin{tabular}{lcccc}
\hline Characteristic & $\begin{array}{c}\text { Control } \\
\mathrm{N}=(11,084)\end{array}$ & $\begin{array}{c}\text { Treatment } \\
\mathrm{N}=(9,988)\end{array}$ & $\begin{array}{c}\text { Coefficient on } \\
\text { Treatment }^{1}\end{array}$ & P-value $^{1}$ \\
\hline Age (policy holders), mean [SD] & 49.3 & 49.0 & -0.272 & 0.521 \\
& {$[9.8]$} & {$[9.8]$} & $(0.423)$ & \\
Percent female (policy holders), N (\%) & 7,847 & 7,363 & 0.029 & 0.11 \\
& $(70.8 \%)$ & $(73.7 \%)$ & $(0.018)$ &
\end{tabular}

Tiers, $\mathrm{N}(\%)$

$\begin{array}{rcccc}\text { Employee only } & 3,337 & 2,715 & -0.029 & 0.521 \\ & (30.1 \%) & (27.2 \%) & (0.045) & \\ \text { Employee and spouse } & 2,633 & 2,448 & 0.008 & 0.602 \\ & (23.8 \%) & (24.5 \%) & (0.014) & \\ \text { Employee and child } & 1362 & 1190 & -0.004 & 0.763 \\ & (12.3 \%) & (11.9 \%) & (0.012) & \\ \text { Employee, spouse, and child } & 3,752 & 3,635 & 0.025 & 0.557\end{array}$

Prior year total expenditures, mean [SD]

$\begin{array}{cccc}11,342.97 & 11,122.81 & -220.158 & 0.711 \\ {[30,277.2]} & {[23,483.1]} & (592.367) & \end{array}$

Prior year total beneficiary costs (premium + OOP costs), mean [SD] or mean (SE)

$\begin{array}{cccc}2901.69 & 2889.82 & -11.866 & 0.949 \\ {[2,932.7]} & {[2,787.4]} & (185.921) & \end{array}$

Prior year number of plans available, mean [SD]

$\begin{array}{cccc}5.3 & 6.6 & 1.315 & 0.079 * \\ {[2.1]} & {[2.1]} & (0.744) & \end{array}$

Notes:

1. From OLS regression of characteristic on treatment. Coefficient (SE).

2. *** Significant at the 1 percent level. ** Significant at the 5 percent level. * Significant at the 10 percent level. 
Table VI

Mean Foregone Savings Difference (2013 - 2012) by Plan Year 2013 Experiment Arm

\begin{tabular}{lccc}
\hline & $\begin{array}{c}\text { Control } \\
\mathrm{N}=(11,084)\end{array}$ & $\begin{array}{c}\text { Treatment } \\
\mathrm{N}=(9,988)\end{array}$ & Regression $^{1}$ \\
\hline Mean Rational Expectations Costs & 153.18 & 54.23 & -98.96 \\
Mean Perfect Backcast Costs & 153.12 & 100.85 & $\begin{array}{c}(99.956) \\
\text { Mean Perfect Forecast Costs }\end{array}$ \\
& 82.47 & 10.50 & -71.97 \\
\hline
\end{tabular}

Notes:

1. From OLS regression of cost outcome on treatment. Coefficient (SE). 
Table VII

Total Costs vs. Number of Plans

\begin{tabular}{|c|c|c|c|c|c|c|}
\hline \multicolumn{7}{|c|}{ All Plans } \\
\hline & $\begin{array}{l}\text { Foregone } \\
\text { Savings }\end{array}$ & $\begin{array}{l}\text { Actual } \\
\text { Costs }\end{array}$ & $\begin{array}{c}\text { Model } \\
\text { Estimated Costs }\end{array}$ & $\begin{array}{c}\text { Model: No } \\
\text { Heterogeneity }\end{array}$ & Inertia & $\begin{array}{c}\text { Benefits Of } \\
\text { Heterogeneity }\end{array}$ \\
\hline 2 & 0.00 & 0.00 & 0.00 & 0.00 & 0.00 & 0.00 \\
\hline 3 & 376.92 & -35.23 & -99.94 & -47.47 & -48.40 & -2.67 \\
\hline 4 & 447.28 & -32.85 & -76.82 & -74.86 & 3.95 & 0.50 \\
\hline 5 & 483.49 & 223.18 & 235.94 & 295.18 & -51.98 & -4.03 \\
\hline 6 & 873.95 & 182.54 & 203.59 & 286.12 & -74.24 & -11.25 \\
\hline 7 & 776.99 & 199.40 & 253.28 & 305.80 & -43.23 & -12.13 \\
\hline 8 & 967.85 & 153.74 & 348.44 & 396.38 & -38.12 & -17.24 \\
\hline 9 & 809.82 & 434.57 & 492.92 & 518.67 & -15.99 & -3.07 \\
\hline 10 & 889.39 & 702.04 & 716.61 & 754.38 & -27.39 & -13.24 \\
\hline \multicolumn{7}{|c|}{ MODA Only } \\
\hline & $\begin{array}{l}\text { Foregone } \\
\text { Savings }\end{array}$ & $\begin{array}{l}\text { Actual } \\
\text { Costs }\end{array}$ & $\begin{array}{c}\text { Model } \\
\text { Estimated Costs }\end{array}$ & $\begin{array}{c}\text { Model: No } \\
\text { Heterogeneity }\end{array}$ & Inertia & $\begin{array}{c}\text { Benefits Of } \\
\text { Heterogeneity }\end{array}$ \\
\hline 2 & 0.00 & 0.00 & 0.00 & 0.00 & 0.00 & 0.00 \\
\hline 3 & 251.78 & 98.00 & -34.44 & -61.30 & 35.72 & 3.76 \\
\hline 4 & 429.95 & 303.14 & 121.28 & 62.62 & 71.64 & 3.89 \\
\hline 5 & 525.31 & 644.89 & 456.39 & 448.52 & 24.13 & -9.40 \\
\hline 6 & 779.23 & 463.30 & 303.78 & 338.95 & -17.67 & -13.30 \\
\hline 7 & 764.28 & 592.51 & 423.74 & 425.08 & 17.23 & -10.22 \\
\hline 8 & 941.55 & 677.67 & 553.48 & 534.87 & 39.63 & -25.98 \\
\hline
\end{tabular}


Table VIII

Simulated Foregone Welfare and Total Costs

\begin{tabular}{|c|c|c|c|c|}
\hline Sample & All Plans & MO & A Only & \\
\hline Metric & $\begin{array}{l}\text { Foregone } \\
\text { Welfare }\end{array}$ & Total Costs & $\begin{array}{c}\text { Foregone } \\
\text { Welfare }\end{array}$ & Total Costs \\
\hline Actual & 939.88 & 2471.64 & 602.74 & 2742.71 \\
\hline Simulated & 1041.32 & 2544.63 & 702.03 & 2821.66 \\
\hline Simulated - 2 plans & 826.23 & 2329.55 & 818.48 & 2938.11 \\
\hline Simulated - 3 plans & 1109.67 & 2612.98 & 738.14 & 2857.77 \\
\hline Simulated - 4 plans & 1008.43 & 2511.75 & 664.45 & 2784.08 \\
\hline Simulated - 5 plans & 1047.78 & 2551.10 & 649.50 & 2769.13 \\
\hline Simulated - 6 plans & 972.35 & 2475.67 & 671.17 & 2790.80 \\
\hline Simulated - 7 plans & 971.19 & 2474.51 & 736.35 & 2855.98 \\
\hline Simulated - 8 plans & 986.77 & 2490.09 & 721.14 & 2840.77 \\
\hline Simulated - 9 plans & 1086.47 & 2589.78 & - & - \\
\hline Simulated - 10 plans & 1068.12 & 2571.44 & - & - \\
\hline $\mathrm{N}=$ & 149,100 & 149,100 & 111,989 & 111,989 \\
\hline
\end{tabular}


Figure I

Mean Overspending

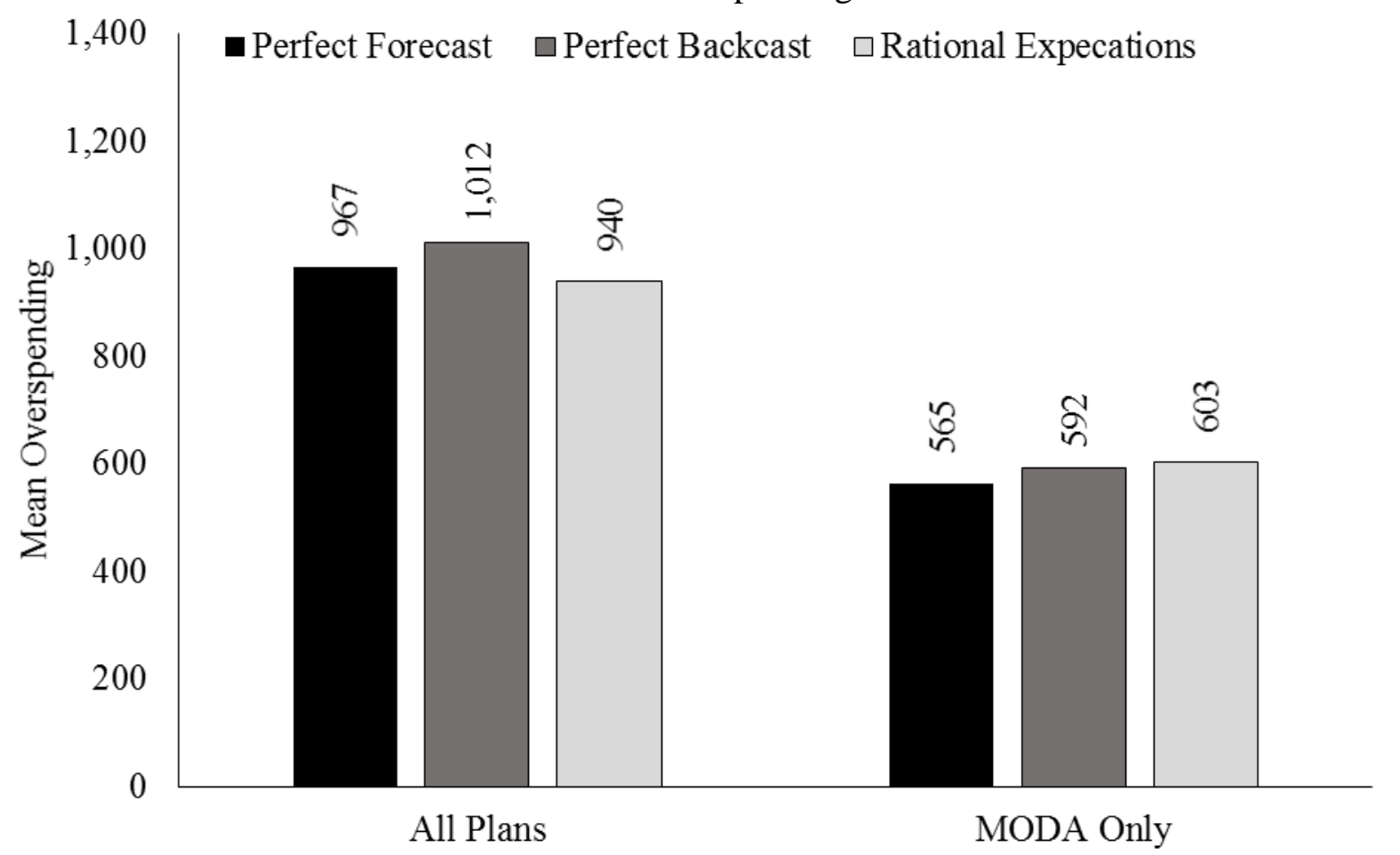


Figure II

Estimated Impact of Recommendation on Choice Probability by Recommendation Quality 0.20

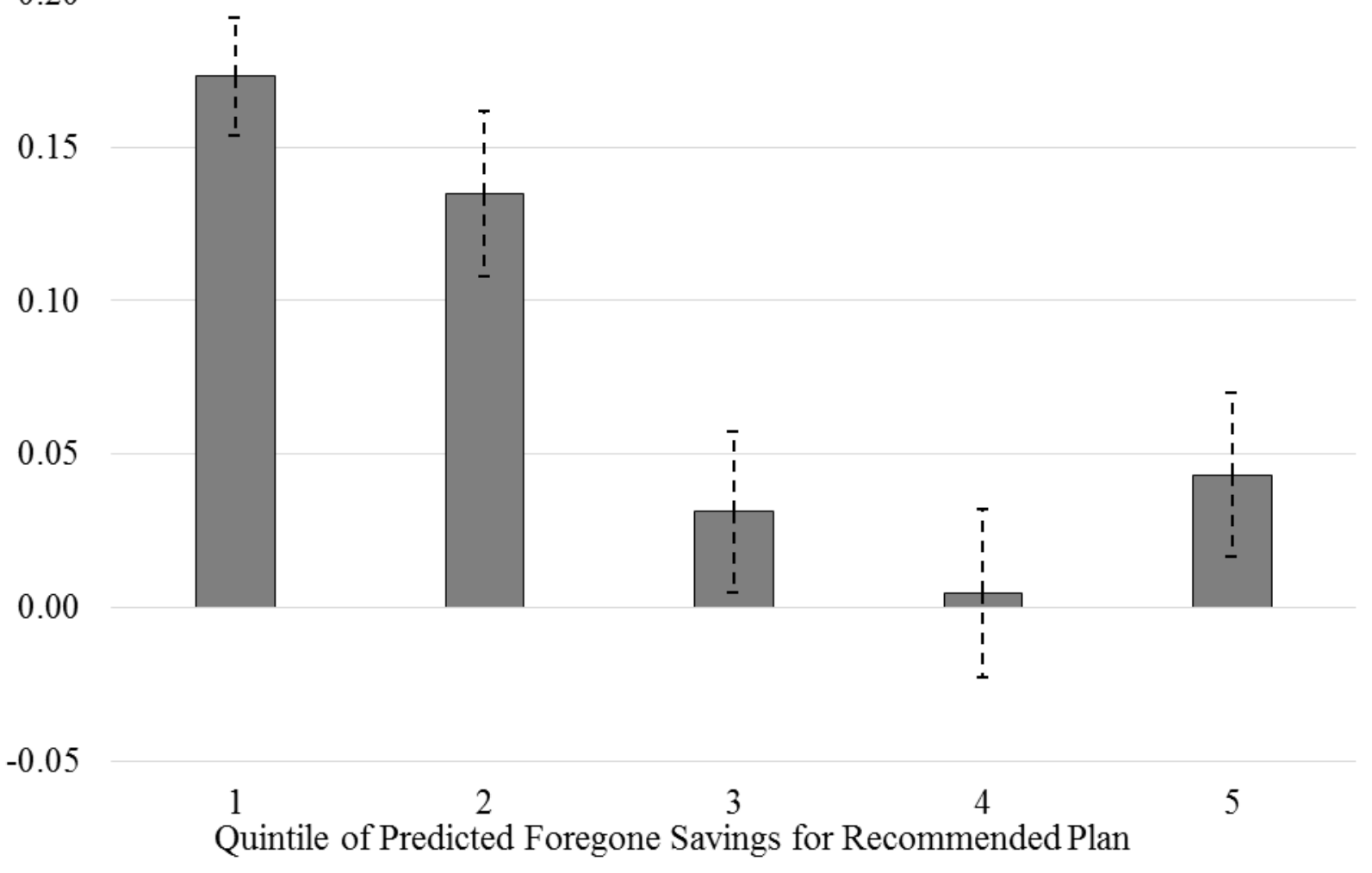


Figure IIIA

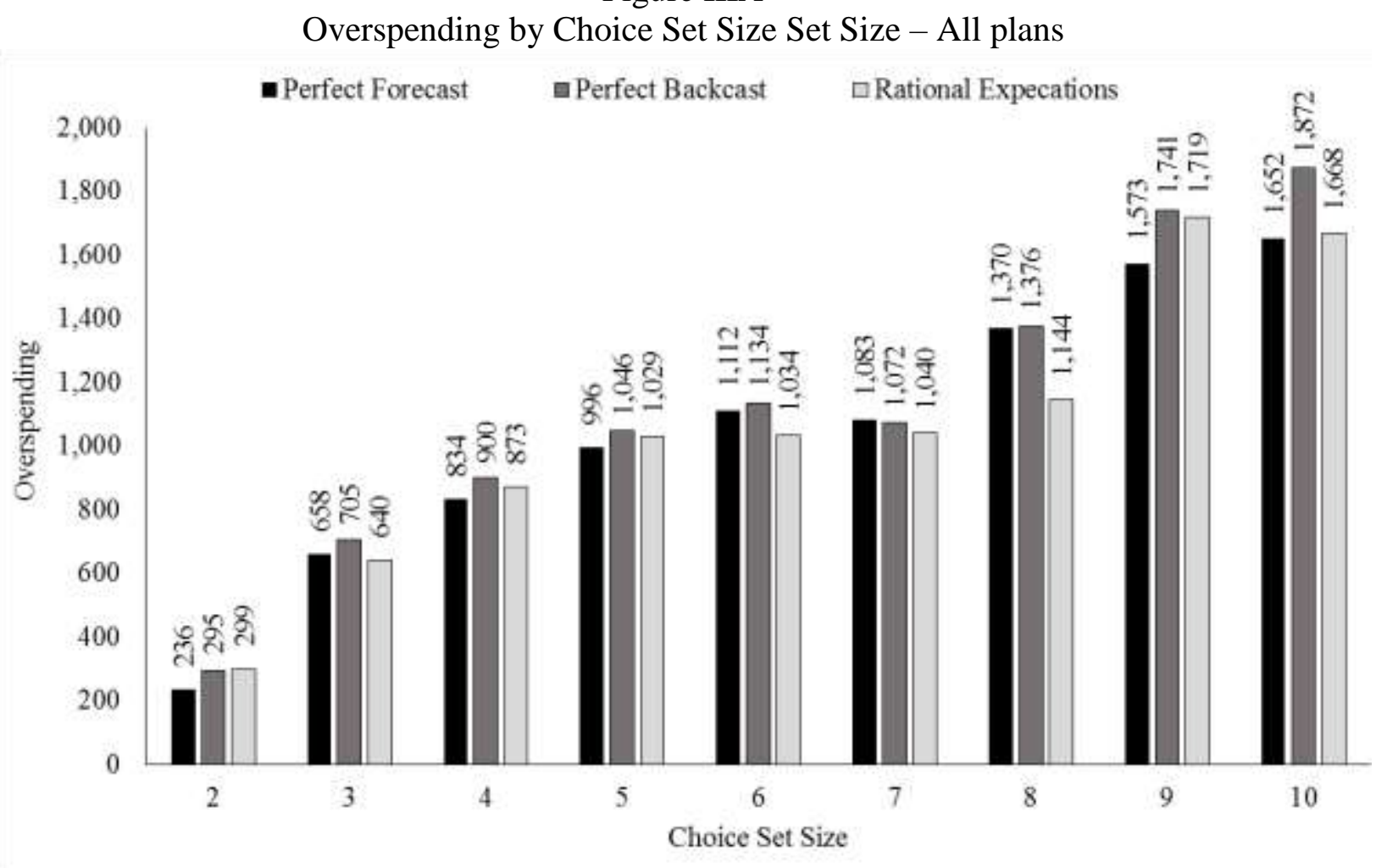


Figure IIIB

Overspending by Choice Set Size Set Size - MODA Only

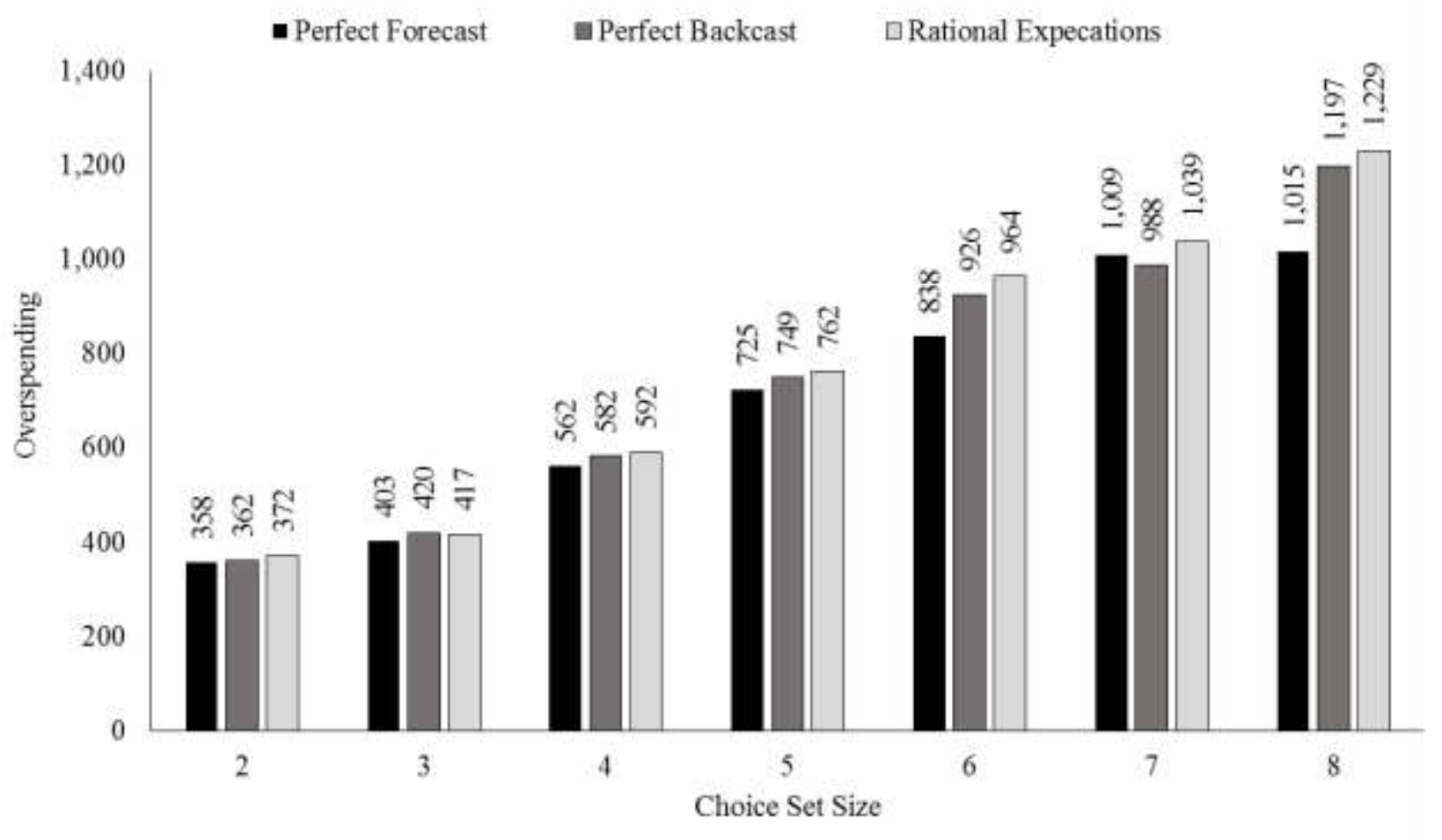


Table A.1

Plan Benefit Structures by Year

\begin{tabular}{|c|c|c|c|c|c|c|c|}
\hline Plan $^{1}$ & 2008 & 2009 & 2010 & 2011 & 2012 & $\operatorname{Plan}^{2}$ & 2013 \\
\hline $\begin{array}{l}\text { Kaiser } \\
\text { Medical } \\
\text { Plan } 1\end{array}$ & $\begin{array}{c}\$ 0 / \$ 0 \\
\mathrm{~N} / \mathrm{A}^{3} \\
\$ 1,000 / \\
\$ 2,000 \\
\mathrm{~N} / \mathrm{A}^{4} \\
\$ 10\end{array}$ & $\begin{array}{c}\$ 0 / \$ 0 \\
\text { N/A } \\
\$ 1,000 / \\
\$ 2,000 \\
\text { N/A } \\
\$ 10\end{array}$ & $\begin{array}{c}\$ 0 / \$ 0 \\
\text { N/A } \\
\$ 1,200 / \\
\$ 2,400 \\
\text { N/A } \\
\$ 10\end{array}$ & $\begin{array}{c}\$ 0 / \$ 0 \\
\text { N/A } \\
\$ 1,200 / \\
\$ 2,400 \\
\text { N/A } \\
\$ 15\end{array}$ & $\begin{array}{c}\$ 0 / \$ 0 \\
\text { N/A } \\
\$ 1,200 / \\
\$ 2,400 \\
\text { N/A } \\
\$ 15\end{array}$ & $\begin{array}{l}\text { Kaiser } \\
\text { Medical } \\
\text { Plan } 1\end{array}$ & $\begin{array}{c}\$ 0 / \$ 0 \\
\text { N/A } \\
\$ 1,500 / \\
\$ 3,000 \\
\text { N/A } \\
\$ 20\end{array}$ \\
\hline $\begin{array}{l}\text { Kaiser } \\
\text { Medical } \\
\text { Plan } 2\end{array}$ & $\begin{array}{c}\$ 0 / \$ 0 \\
\text { N/A } \\
\$ 600 / \\
\$ 1,200 \\
\text { N/A } \\
\$ 5\end{array}$ & $\begin{array}{c}\$ 0 / \$ 0 \\
\text { N/A } \\
\$ 600 / \\
\$ 1,200 \\
\text { N/A } \\
\$ 5\end{array}$ & - & - & - & $\begin{array}{l}\text { Kaiser } \\
\text { Medical } \\
\text { Plan } 2\end{array}$ & - \\
\hline $\begin{array}{l}\text { Kaiser } \\
\text { Medical } \\
\text { Plan 1A }\end{array}$ & - & $\begin{array}{c}\$ 0 / \$ 0 \\
\text { N/A } \\
\$ 1,500 / \\
\$ 3,000 \\
\text { N/A } \\
\$ 25\end{array}$ & $\begin{array}{c}\$ 0 / \$ 0 \\
\text { N/A } \\
\$ 1,500 / \\
\$ 3,000 \\
\text { N/A } \\
\$ 20\end{array}$ & $\begin{array}{c}\$ 100 / \$ 300 \\
\text { N/A } \\
\$ 2,000 / \\
\$ 4,000 \\
\text { N/A } \\
\$ 20\end{array}$ & $\begin{array}{c}\$ 150 / \$ 450 \\
\text { N/A } \\
\$ 2,000 / \\
\$ 4,000 \\
\text { N/A } \\
\$ 20\end{array}$ & $\begin{array}{l}\text { Kaiser } \\
\text { Medical } \\
\text { Plan 1A }\end{array}$ & $\begin{array}{c}\$ 200 / \$ 600 \\
\text { N/A } \\
\$ 2,200 / \\
\$ 4,400 \\
\text { N/A } \\
\$ 25\end{array}$ \\
\hline $\begin{array}{l}\text { ODS } \\
\text { Medical } \\
\text { Plan } 3\end{array}$ & $\begin{array}{c}\$ 100 / \$ 300^{5} \\
\text { N/A } \\
\$ 500^{6} \\
\$ 1,500 \\
\$ 10\end{array}$ & $\begin{array}{c}\$ 100 / \$ 300 \\
\text { N/A } \\
\$ 500 \\
\$ 1,500 \\
\$ 10\end{array}$ & $\begin{array}{c}\$ 200 / \$ 600 \\
\text { N/A } \\
\$ 1,200 \\
\$ 2,400 \\
\$ 15\end{array}$ & $\begin{array}{c}\$ 200 / \$ 600 \\
\text { N/A } \\
\$ 1,500 / \\
\$ 4,500 \\
\$ 3,000 / \\
\$ 9,000 \\
\$ 25\end{array}$ & $\begin{array}{c}\$ 200 / \$ 600 \\
\text { N/A } \\
\$ 1,500 / \\
\$ 4,500 \\
\$ 3,000 / \\
\$ 9,000 \\
\$ 25\end{array}$ & $\begin{array}{l}\text { MODA } \\
\text { Medical } \\
\text { Plan A }\end{array}$ & $\begin{array}{c}\$ 200 / \$ 600 \\
\text { N/A } \\
\$ 2,000 / \\
\$ 6,000 \\
\$ 4,000 / \\
\$ 12,000 \\
\$ 20\end{array}$ \\
\hline $\begin{array}{l}\text { ODS } \\
\text { Medical } \\
\text { Plan } 4\end{array}$ & $\begin{array}{c}\$ 100 / \$ 300 \\
\text { N/A } \\
\$ 1,000 \\
\$ 2,000 \\
\$ 15\end{array}$ & $\begin{array}{c}\$ 100 / \$ 300 \\
\text { N/A } \\
\$ 1,000 \\
\$ 2,000 \\
\$ 15\end{array}$ & $\begin{array}{c}\$ 200 / \$ 600 \\
\mathrm{~N} / \mathrm{A} \\
\$ 1,500 \\
\$ 3,000 \\
\$ 25\end{array}$ & $\begin{array}{c}\$ 300 / \$ 900 \\
\text { N/A } \\
\$ 2,000 / \\
\$ 6,000 \\
\$ 4,000 / \\
\$ 12,000 \\
\$ 25\end{array}$ & $\begin{array}{c}\$ 300 / \$ 900 \\
\text { N/A } \\
\$ 2,000 / \\
\$ 6,000 \\
\$ 4,000 / \\
\$ 12,000 \\
\$ 25\end{array}$ & $\begin{array}{l}\text { MODA } \\
\text { Medical } \\
\text { Plan B }\end{array}$ & $\begin{array}{c}\$ 350 / \\
\$ 1050 \\
\text { N/A } \\
\$ 2,400 / \\
\$ 7,200 \\
\$ 4,800 / \\
\$ 14,400 \\
\$ 20 \\
\$ 500 /\end{array}$ \\
\hline $\begin{array}{l}\text { ODS } \\
\text { Medical } \\
\text { Plan } 5\end{array}$ & $\begin{array}{c}\$ 200 / \$ 600 \\
\text { N/A } \\
\$ 1,000 \\
\$ 2,000 \\
\$ 20\end{array}$ & $\begin{array}{c}\$ 200 / \$ 600 \\
\text { N/A } \\
\$ 1,000 \\
\$ 2,000 \\
\$ 20\end{array}$ & $\begin{array}{c}\$ 200 / \$ 600 \\
\mathrm{~N} / \mathrm{A} \\
\$ 1,800 \\
\$ 3,600 \\
\$ 25\end{array}$ & $\begin{array}{c}\$ 300 / \$ 900 \\
\mathrm{~N} / \mathrm{A} \\
\$ 2,000 / \\
\$ 6,000 \\
\$ 4,000 / \\
\$ 12,000 \\
\$ 25\end{array}$ & $\begin{array}{c}\$ 300 / \$ 900 \\
\mathrm{~N} / \mathrm{A} \\
\$ 2,000 / \\
\$ 6,000 \\
\$ 4,000 / \\
\$ 12,000 \\
\$ 25\end{array}$ & $\begin{array}{l}\text { MODA } \\
\text { Medical } \\
\text { Plan C }\end{array}$ & $\begin{array}{c}\$ 1,500 \\
\text { N/A } \\
\$ 2,600 / \\
\$ 7,800 \\
\$ 5,200 / \\
\$ 15,600 \\
\$ 20\end{array}$ \\
\hline
\end{tabular}




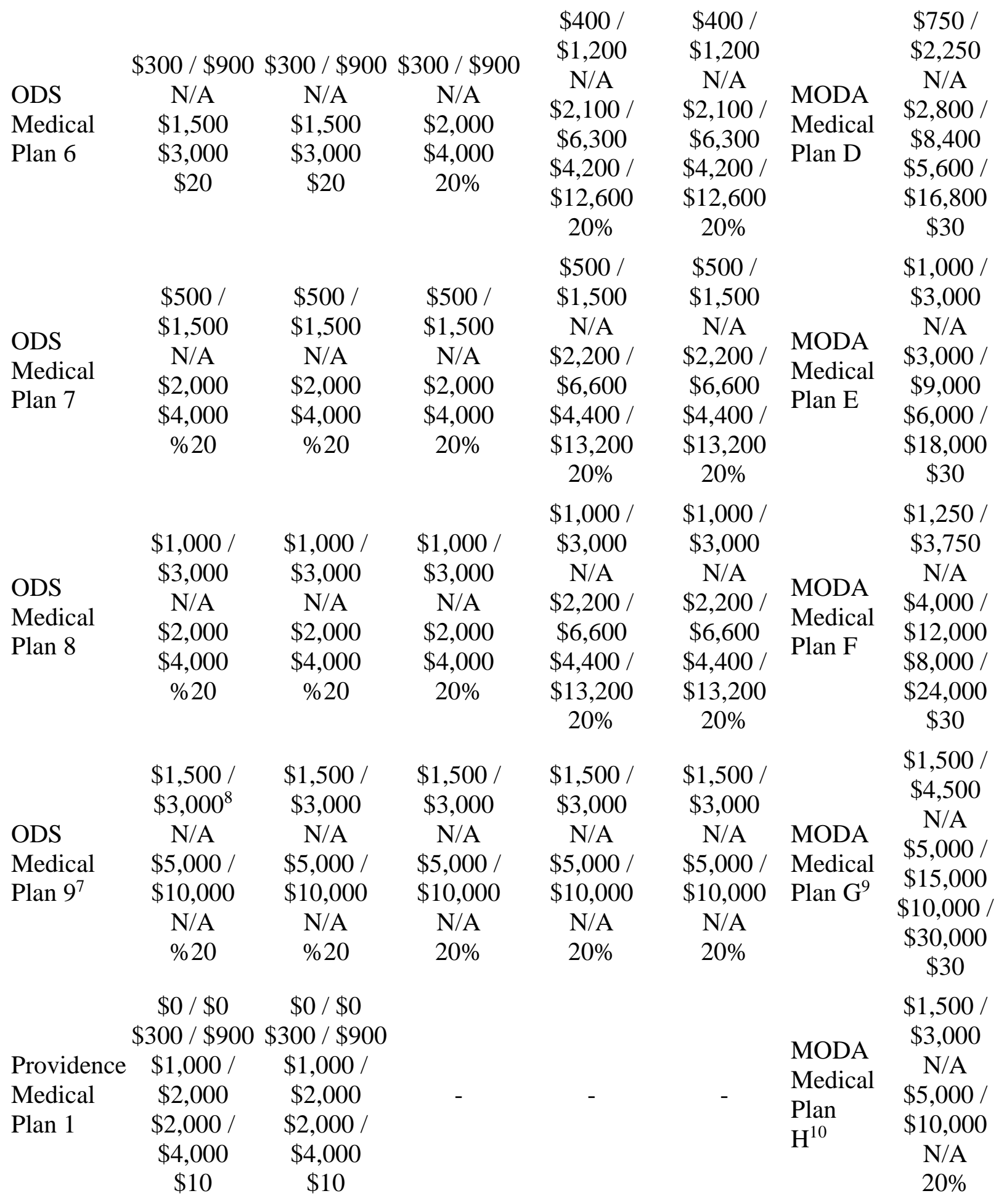




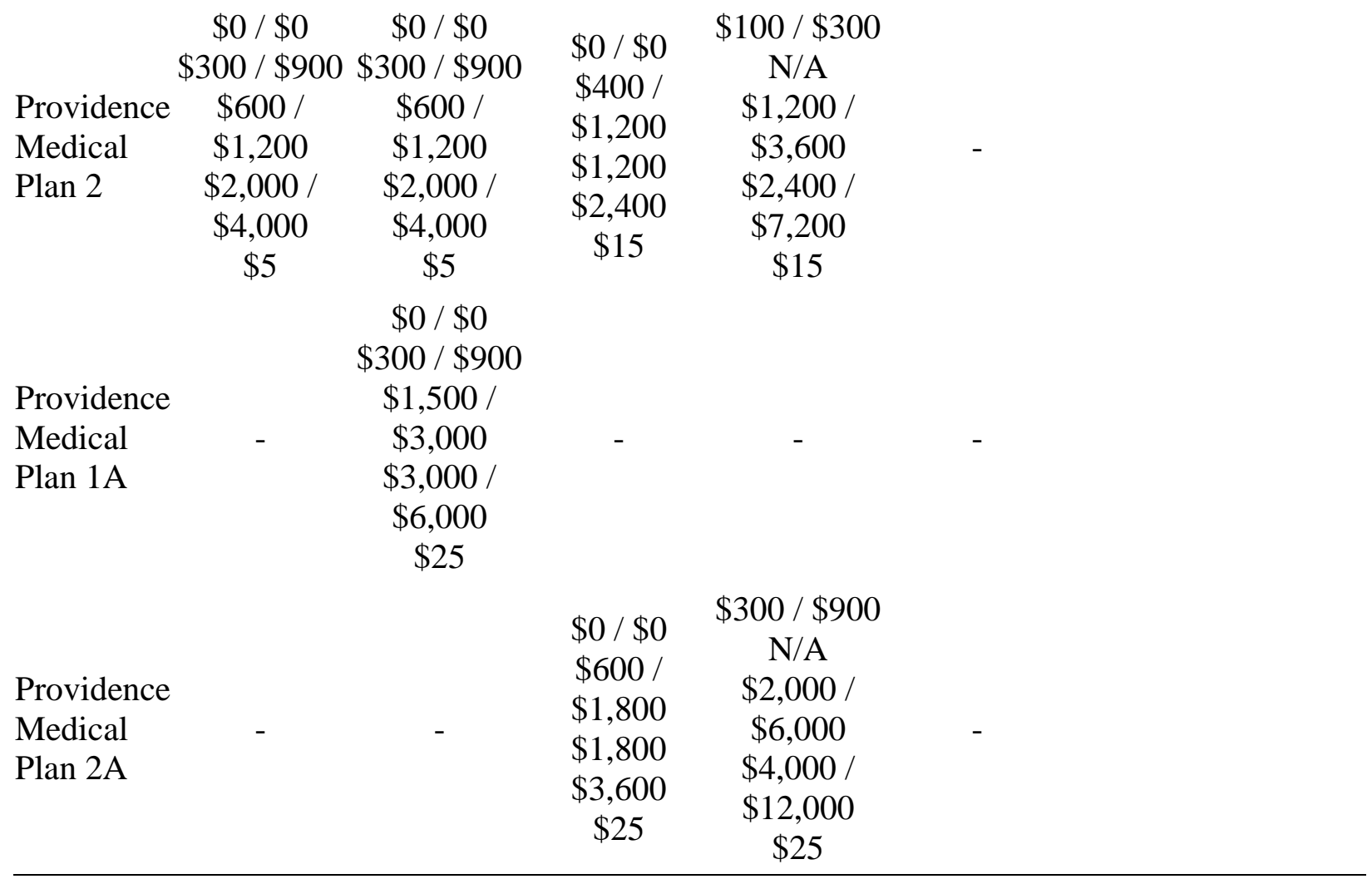

Notes:

1. Data presented is: Line 1 - in-network individual deductible / in-network family deductible, line 2 - out of-network individual deductible / out of-network family deductible, line 3 - innetwork individual OOP maximum / in-network family OOP maximum, line 4 - out ofnetwork individual OOP maximum / out of-network family OOP maximum, beneficiary liability (dollar value copay or percent coinsurance) for non-specialist office visit or primary care service.

2. As above, we do not wish to suggest row equivalence of plans before and after the name change from ODS to MODA. Plans here are simply listed alphabetically.

3. N/A in the second line indicated that no out of network deductible exists, either because coverage is restricted to a network (Kaiser) or because the deductible is combined for in and out of network services (OMED/MODA/Providence).

4. N/A in the fourth line indicated that no out of network OOP max exists, either because coverage is restricted to a network (Kaiser) or because the OOP max is combined for in and out of network services (OMED/MODA/Providence).

5. ODS / MODA plan deductibles in plans other than OMED9 and MMEDH is a per person amount up to a total family maximum. E.g. in OMED3 in 2008, the deductible is $\$ 100$ per member, with a $\$ 300$ per family maximum, thus individual policy holders would have a $\$ 100$ deductible, policy holders with 1 dependent would have a $\$ 200$ deductible, and policy holders with 2 or more dependents (for 3 or more total members) would have a $\$ 300$ deductible.

6. From 2008 - 2010, OOP maximum for OMED plans 3-8 was calculated based on family size using the per person amount presented, as such there is no single family amount. The same procedure was used for Providence plans in 2010.

7. In 2011 and 2012 OMED9 was an HSA compliant plan. 
8. OMED9 and MMEDH did not use per person deductibles as described in note 5. There was one individual amount applied to only individual policy holders and one family amount applied to all plans with 2 or more beneficiaries.

9. MMEDG was a non-HSA compliant high deductible plan in 2013.

10. MMEDH was an HSA compliant plan in 2013.

In each cell, the first line presents the in-network individual deductible and in-network family deductible. The second line presents out of-network individual deductible and out of-network family deductible. If there is only one combined deductible for in and out of network service combined, it is presented on line 1 and line 2 reads "N/A". The third line presents in-network individual OOP maximum (or per person OOP maximum) and in-network family OOP maximum. The fourth line presents out of-network individual OOP maximum and out of-network family OOP maximum. Some plans had explicit individual (only policy holder covered) and family (any dependents covered) OOP maximums, while other plans had a variable OOP maximum with a per person OOP maximum, subject to a cap - generally 3 times the individual OOP maximum. The final line presents beneficiary liability (dollar value copay or percent coinsurance) for nonspecialist office visit or primary care service.

Kaiser and Providence medical plans, and the high deductible plan (OMED9 or MMEDH) offered by ODS/MODA included a prescription drug plan. Districts offering non-high deductible OMED/MODA plans could choose to offer one or two of three total OMED/MODA drug plans. When a district had choice over the drug plans to offer, medical and drug coverage were still offered as a package - individuals beneficiaries could not independently choose medical and drug plans, but rather selected one plan with both types of coverage. Districts could choose to offer two Kaiser dental plans, and one Kaiser vision plan to beneficiaries that chose a Kaiser medical plan. Districts could offer up to three total dental plans, choosing from five to six OMED/MODA dental plans and one to two outside plans, depending on year. Districts could offer one of five vision plans in addition to the Kaiser vision plan. 
Table A.2

Sample Selection

\begin{tabular}{|c|c|c|c|c|c|c|}
\hline Criteria & 2008 & 2009 & 2010 & 2011 & 2012 & 2013 \\
\hline $\begin{array}{l}\text { 1. Number of policy holders in the } \\
\text { eligibility file }\end{array}$ & 63,708 & 65,385 & 65,222 & 63,110 & 63,234 & 63,378 \\
\hline $\begin{array}{l}\text { 2. Number of policy holders with } \\
\text { coverage }^{1}\end{array}$ & 59,638 & 59,908 & 58,359 & 55,864 & 55,346 & 55,335 \\
\hline $\begin{array}{l}\text { 3. Number of policy holders not } \\
\text { covered by COBRA and not self-pay } \\
\text { retirees }\end{array}$ & 51,568 & 51,533 & 50,402 & 47,808 & 47,758 & 48,201 \\
\hline $\begin{array}{l}\text { 4. Number of policy holders that did } \\
\text { not switch district, employee type, } \\
\text { member type, or tier mid-year }{ }^{2}\end{array}$ & 50,300 & 50,921 & 49,693 & 47,262 & 47,107 & 47,622 \\
\hline $\begin{array}{l}\text { 5. Number of policy holders in known } \\
\text { districts }^{3}\end{array}$ & 49,327 & 49,904 & 48,642 & 46,215 & 46,085 & 46,569 \\
\hline $\begin{array}{l}\text { 6. Number of policy holders with } \\
\text { premium and contribution data }\end{array}$ & 48,602 & 49,172 & 47,862 & 45,539 & 44,812 & 42,096 \\
\hline $\begin{array}{l}\text { 7. Number of policy holders with at } \\
\text { least } 2 \text { choices }\end{array}$ & 48,051 & 49,075 & 47,799 & 45,478 & 44,747 & 42,046 \\
\hline \multicolumn{7}{|l|}{ Perfect Foresight sample } \\
\hline $\begin{array}{l}\text { 8A. Number of policy holders with } \\
\text { continuous eligibility for one year } \\
\text { following plan choice }\end{array}$ & 41,862 & 42,559 & 40,819 & 38,828 & 37,968 & 35,001 \\
\hline $\begin{array}{l}\text { 9A. Number policy holders with all } \\
\text { individuals covered by only one plan } \\
\text { and with claims from only one plan }{ }^{4}\end{array}$ & 38,566 & 39,423 & 38,320 & 36,483 & 35,763 & 32,871 \\
\hline $\begin{array}{l}\text { 10A. Number of policy holders in } \\
\text { intact families } 5\end{array}$ & 37,648 & 38,456 & 37,130 & 35,299 & 34,545 & 31,687 \\
\hline \multicolumn{7}{|c|}{ Perfect Backcast and Rational Expectations Sample } \\
\hline $\begin{array}{l}\text { 8B. Number of policy holders with } \\
\text { continuous eligibility for one year } \\
\text { prior to and following plan choice }\end{array}$ & -6 & 38,618 & 37,754 & 36,092 & 34,509 & 30,913 \\
\hline $\begin{array}{l}\text { 9B. Number policy holders with all } \\
\text { individuals covered by only one plan } \\
\text { and with claims from only one plan }\end{array}$ & - & 35,080 & 34,600 & 33,374 & 31,897 & 28,517 \\
\hline $\begin{array}{l}\text { 10B. Number of policy holders in } \\
\text { intact families } 5\end{array}$ & - & 32,343 & 30,824 & 30,608 & 29,283 & 26,042 \\
\hline
\end{tabular}

Notes:

1. The eligibility file has observations for employees that declined coverage. These employees are dropped here.

2. A change in these characteristics would change the choice of plans available to an employee.

3. To protect patient confidentiality, our data contains only a randomly generated district identifying number for districts with very few employees. We cannot link these district numbers to district specific contribution data, so these observations are dropped. 
4. If two family members are employees it is possible for a beneficiary to be a subscriber on one plan and a dependent on another. It is also possible for a child to be a dependent on multiple plans. These double coverage families are dropped.

5. If any member of a family is dropped based on steps $1-9$, we must drop the entire family to accurately model choice of coverage at the family level.

6. We do not observe 2007 eligibility and cannot create a backward looking sample in 2008 . 
Table A.3

Rational Expectations Sensitivity Analyses

All Plans MODA Only

Foregone welfare Foregone welfare

\begin{tabular}{|c|c|c|c|}
\hline & & $\begin{array}{c}\text { Foregone welfare } \\
\text { mean }[\mathrm{SD}]\end{array}$ & $\begin{array}{c}\text { Foregone welfare } \\
\text { mean }[\mathrm{SD}]\end{array}$ \\
\hline \multicolumn{4}{|c|}{ Regression Model $^{1}$} \\
\hline & \multirow[t]{2}{*}{2,000 draws } & 940.36 & 602.14 \\
\hline & & {$[1,271.56]$} & {$[1,084.65]$} \\
\hline & \multirow[t]{2}{*}{10,000 draws } & 938.42 & 601.73 \\
\hline & & {$[1,269.46]$} & {$[1,084.56]$} \\
\hline & \multirow[t]{2}{*}{20,000 draws } & 938.48 & 602.23 \\
\hline & & {$[1,269.32]$} & {$[1,085.71]$} \\
\hline \multicolumn{4}{|l|}{ Decile Model ${ }^{2}$} \\
\hline & \multirow[t]{2}{*}{2,000 draws } & 938.48 & 601.66 \\
\hline & & {$[1,269.32]$} & {$[1,085.90]$} \\
\hline & \multirow[t]{2}{*}{10,000 draws } & 937.73 & 600.09 \\
\hline & & {$[1,272.67]$} & {$[1,083.34]$} \\
\hline & \multirow[t]{2}{*}{20,000 draws } & 938.18 & 600.12 \\
\hline & & {$[1,272.87]$} & {$[1,083.27]$} \\
\hline \multicolumn{4}{|l|}{3 Cell Model $^{3}$} \\
\hline & \multirow{2}{*}{2,000 draws } & 912.04 & 623.28 \\
\hline & & {$[1,262.61]$} & {$[1,135.00]$} \\
\hline & \multirow{2}{*}{10,000 draws } & 920.01 & 624.56 \\
\hline & & {$[1,267.35]$} & {$[1,136.47]$} \\
\hline & \multirow[t]{2}{*}{20,000 draws } & 919.58 & 624.29 \\
\hline & & {$[1,267.33]$} & {$[1,135.32]$} \\
\hline
\end{tabular}

Notes:

1. Results presented in this paper use the regression model with 2,000 draws. In the Regression Model we create deciles of each of the three dimensions of risk predicted by the John's Hopkins Software and add an eleventh category in each dimension for zero costs. We then regress year $t$ costs on these three categorical variables (calculated based on year t-1 claims) and generate a predicted cost in year t. Next we create deciles of this predicted cost variable to yield 10 groups of similarly at risk individuals.

2. In the Decile Model we sum the three raw risk scores predicted by the Johns Hopkins software, create deciles of this total risk score, and add an eleventh category for zero predicted costs.

3. In the 3 Cell Model we create quintiles of the risk predicted by the John's Hopkins Software, and create a sixth category in each dimension for zero predicted expenditure. We then combine these three categorical variables, each with six levels, to create a cell for each individual, with $216\left(6^{3}\right)$ possible cells. We then combine all individuals not in the top or bottom cell into one cell, resulting in 3 total cells. 
Figure A.1

Informed Enrollment Screenshot 1

\section{INFORMED ENROLLMENT FOR ABC GLOBAL}

\section{HEALTHCARE HISTORY}

PROGRESS:

What makes up your healthcare costs? Check out the charts below to view your recent history.

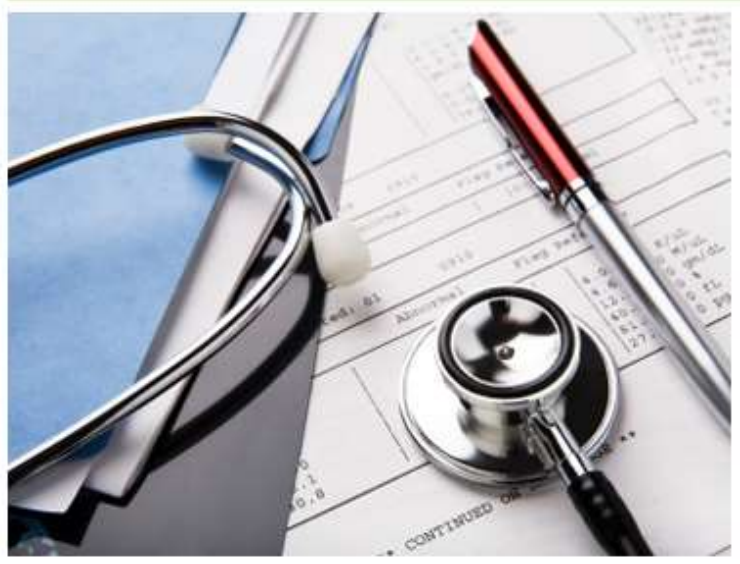

\section{- Your total healthcare costs}

$\$ 11,240$

Your employer contributes a significant amount toward your healthcare and other benefits.

Timeframe: Jan 2013 - Jun 2013 | Jan 2012 - 2012

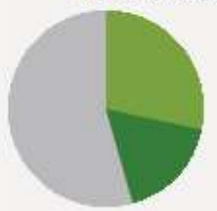

Your annual premiums $(\$ 3,200)$

You paid out-of-pocket $(\$ 1,945$

ABC Global paid $(\$ 6,095)$

Source: Your healthcare claims Jan 2012 - Dec 2012

$\oplus$ View your out-of-pocket costs

$\$ 1,945$

4 Back

\section{Continue}

2013 Truven Health Analytics Inc.

Terms of Use | Privacy Policy | Disclaimers | Contact info 
Figure A.2

Informed Enrollment Screenshot 2

\section{INFORMED ENROLLMENT FOR ABC GLOBAL}

WHO'S INSURED

PROGRESS:

Tell us about changes (if any) to who will be insured next year by adding or removing people.

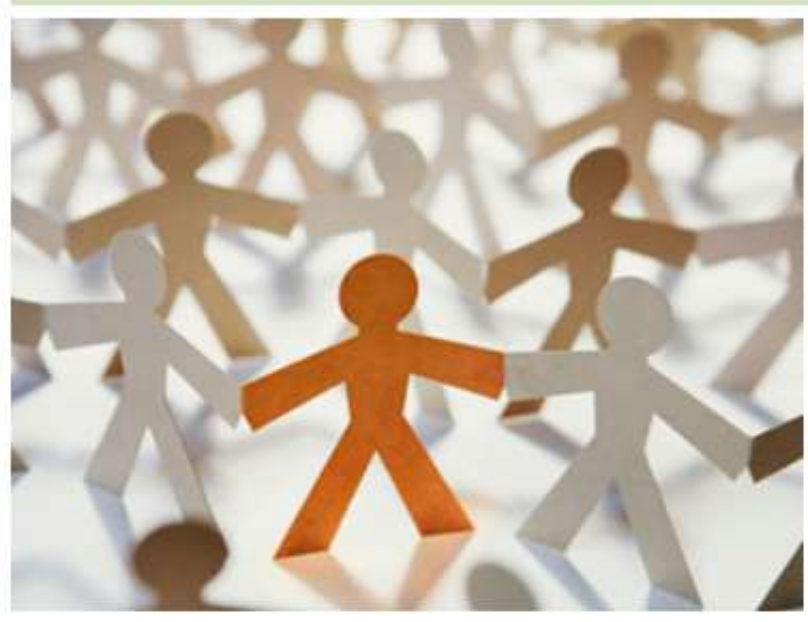

1 Back $\oplus$ Reset this page

(c) 2013 Truven Health Analytics Inc.

Terms of Use | Privacy Policy | Disclaimers | Contact info

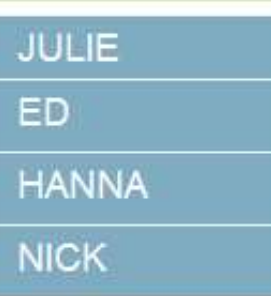

Employee

Spouse

Dependent

Dependent

Tell us about a new covered person

Continue

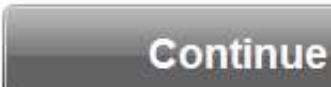

ABC Global

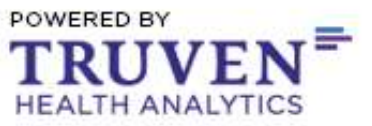


Figure A.3

Informed Enrollment Screenshot 3

INFORMED ENROLLMENT FOR ABC GLOBAL
NEW HEALTHCARE SERVICES
Would you like to include any major services that you expect in the next year?
If so, you can add them here.

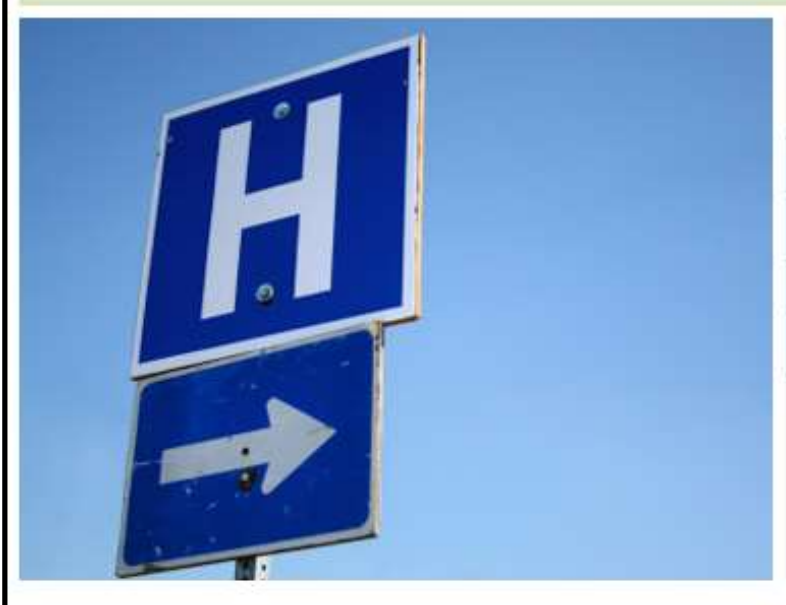

\begin{tabular}{ll} 
& $\begin{array}{l}\text { Major Healthcare Services } \\
\text { (for example, a planned pregnancy, } \\
\text { or new condition) }\end{array}$ \\
JUL_E & Add a major healthcare service \\
ED & Add a major healthcare service \\
\hline HANNA & Add a major healthcare service \\
\hline NICK & Add a major healthcare service
\end{tabular}

$\checkmark$ Back $\quad 2$ Reset this page

\section{Continue}

(C) 2013 Truven Health Analytics Inc.

Terms of Use | Privacy Policy | Disclaimers | Contact info

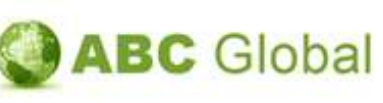

POWERED BY TEALTH ANALYTICS 
Figure A.4

Informed Enrollment Screenshot 4

\section{INFORMED ENROLLMENT FOR ABC GLOBAL}

HEALTHCARE NEEDS

PROGRESS:

The levels shown below are based on your recent healthcare and any service(s) you added. You can move the sliders if you want to adjust them.

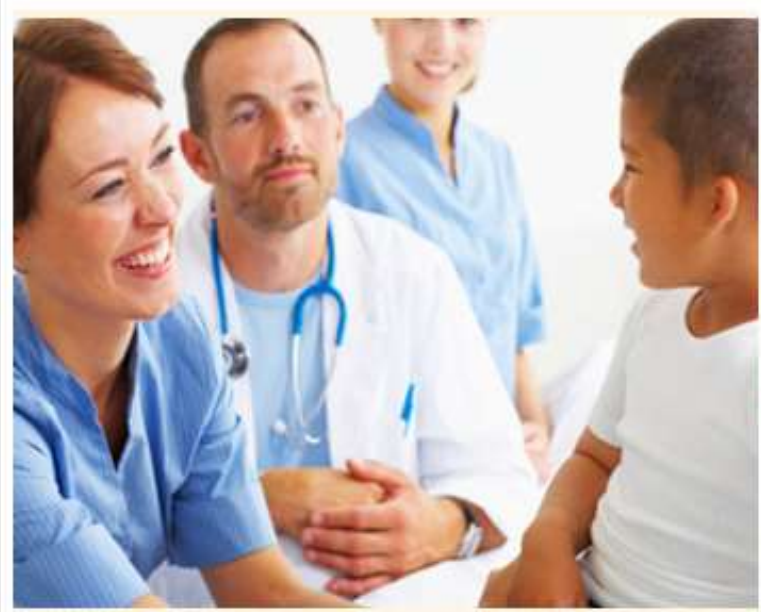

Back

$$
\text { Reset this page }
$$

(C) 2013 Truven Health Analytics Inc.

Terms of Use | Privacy Policy | Disclaimers | Contact Info

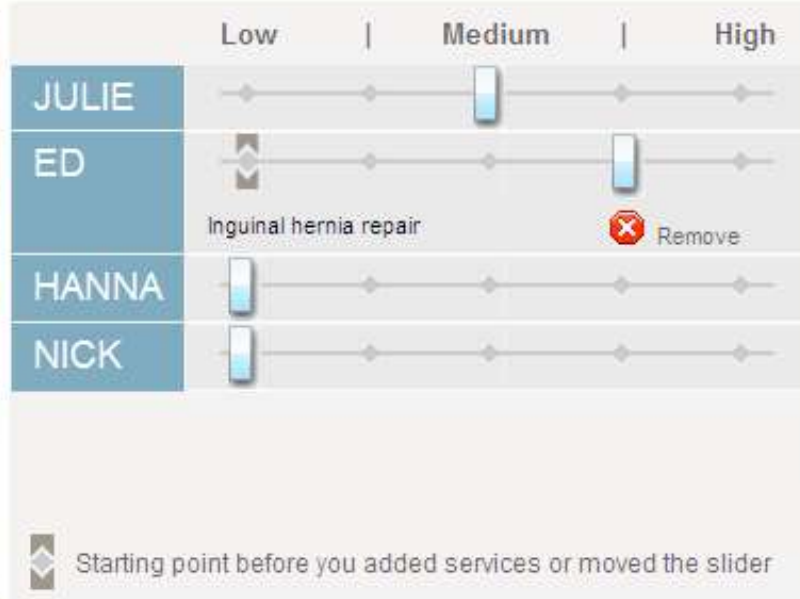

Continue

ooveracos or 
Figure A.5

Informed Enrollment Screenshot 5

\section{YOUR EMPLOYER'S BENEFIT CONTRIBUTION}

CLOSE

Please enter the Monthly amount your employer will contribute towards your medical benefits during the 2012-13 plan year. The amount you enter here will be used to subtract the Employer's Contribution from the Total Premium amount for each medical plan option.

My Employer's Contribution will be:

$\$$

The adjusted amount will be presented on the next screen as "Your Annual Premiums."

\section{Continue}


Figure A.6

Informed Enrollment Screenshot 6

\section{INFORMED ENROLLMENT FOR ABC GLOBAL}

THE RIGHT PLAN

\section{Your 2014 Health Plan Cost Comparison}

PROGRESS:

Compare the estimated total costs for your health plan options for 2014.

(Reminder: Your 2013 health plan is PreferredNet PPO)

\begin{tabular}{|l|r|l|l|}
\hline Plan (Insurer) & $\begin{array}{r}\text { Your estimated total cost } \\
\text { (Family coverage) }\end{array}$ & $\square$ Your annual premiums & $\square$ Your estimated out- \\
of-pocket costs
\end{tabular}

\section{Things to Think About}

It's important to consider premium amounts AND the potential out-of-pocket amounts you would pay to get a fuller picture of your healthcare costs.

More $s$

\section{Useful Documents}

- 2014 Health Plan Summary Comparison

- 2014 Health Plan Changes

\&ack

\section{Continue}

Note: Plan comparison information is provided only as a guide to assist you in evaluating your benefit plan options and is based on your historic claims and other information you have provided. These estimates and comparisons are intended for your general use only and are not a substitute for professional advice from financial or medical professionals. Truven Health Analytics is not liable to you for damages of any kind resulting from your access to or your use of the information provided. If you have further questions about your use of this information, contact your Sponsoring Organization. 